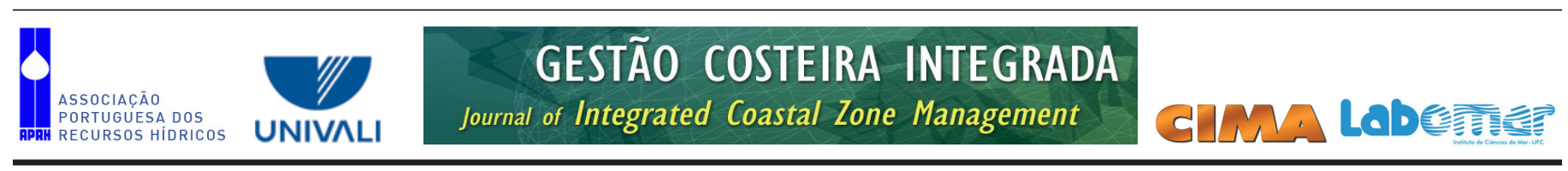

http://www.aprh.pt/rgci/pdf/rgci-411_Marino.pdf | DOI:10.5894/rgci411

\title{
Variações granulométricas ao longo da costa da região metropolitana de Fortaleza, Ceará, Brasil *
}

\section{Grain size variations along the Fortaleza metropolitan region coastline, Ceará, Brazil}

\author{
Márcia Thelma Rios Donato Marino ${ }^{\circledR}, 1$, George Satander Sá Freire ${ }^{2}$, Norberto Olmiro Horn Filho ${ }^{3}$
}

\section{RESUMO}

Este trabalho apresenta um estudo da distribuição longitudinal e transversal do tamanho do grão em praias arenosas da Região Metropolitana de Fortaleza (RMF), estado do Ceará, Brasil. Parâmetros estatísticos foram utilizados para a comparação da distribuição sedimentar ao longo da costa e entre os subambientes praiais. A coleta de 99 amostras de sedimentos superficiais da faixa praial, durante a maré de sizígia, permitiu observar mudanças sazonais em 3 períodos distintos: chuvoso, transição e estiagem. Esta faixa litorânea desenvolveu praias com níveis diferenciados de energia hidrodinâmica, expostas e semiexpostas, protegidas pelas faixas alongadas e descontínuas dos arenitos de praia, os quais diminuem a energia das ondas, protegendo as praias da erosão costeira. Os setores extremos são os mais dinâmicos e de maior susceptibilidade à ação das ondas e ressacas. A dinâmica sedimentar é caracterizada pela grande mobilidade de sedimentos ao longo da praia em resposta à açáo das correntes de deriva litorânea, entre a parte emersa e submersa, e às variaçóes meteorológicas. Por encontrar-se inserida totalmente na RMF, a planície costeira entre as praias do Futuro e do Porto das Dunas sofreu e sofre fortemente as consequências negativas de um rápido processo de urbanização e adensamento demográfico, trazendo desequilíbrios significativos nas relaçóes sociedade versus natureza e tendo como efeitos mais marcantes a degradação ambiental. As características granulométricas desta faixa litorânea são fortemente condicionadas pela influência dos agentes hidrodinâmicos, eólicos e meteorológicos, associados ao tipo, orientação e localização da praia e à proximidade e tipo da área fonte de sedimentos. Recomenda-se para futuros trabalhos a realização de sondagens estratigráficas ao longo da planície costeira, a análise de detalhe dos sedimentos quanto à morfoscopia e mineralogia, o monitoramento morfodinâmico e sedimentológico da faixa praial, a batimetria e faciologia da antepraia e plataforma continental interna adjacente, e a realização de estudos prévios (muitas vezes de médio e longo prazo) para a construção de obras e empreendimentos costeiros.

Palavras-chave: Análise textural; Variações sazonais; Morfodinâmica praial.

@- Corresponding author: marino@unifor.br

1 - Universidade Federal do Ceará (UFC), Programa de Pós-Graduação em Geologia, Campos do Pici, Bloco 912, CEP 60455-760, Fortaleza, Ceará, Brasil. I Universidade de Fortaleza (UNIFOR), Campus da UNIFOR, Av. Washington Soares, 1321, Edson Queiroz, CEP 60.811-905, Fortaleza, Ceará, Brasil. 2 - Universidade Federal do Ceará (UFC), Departamento de Geologia, Laboratório de Geologia Marinha, Campos do Pici, Bloco 912, CEP 60455-760, Fortaleza, Ceará, Brasil

3 - Universidade Federal de Santa Catarina (UFSC), Programa de Pós-graduação em Geografia, Campus Universitário Trindade, Caixa Postal 476, CEP: 88.040 - 970, Florianópolis (SC) - Brasil 


\section{ABSTRACT}

This paper presents a study of the long shore and cross-shore grain size distribution of sandy beaches along the Fortaleza Metropolitan Region (RMF) coastline. Statistical parameters were used to compare grain sizes along the coast and among the subgroup of beaches. The different percentage of the grain size distribution and statistical parameters were used for comparisons. The collection of 99 samples of surface sediments during spring tide allowed for the observation of seasonal changes in three distinct periods: rainy, dry and transition seasons. This coastline developed beaches with different hydrodynamic energy levels, exposed and semi-exposed, protected by elongated strips and discontinuous beachrocks, which reduce wave energy, protecting the beaches from coastal erosion. The extreme sectors are the most dynamic and of greatest susceptibility to the wave action and storm surge. The sedimentary dynamics is characterized by the high mobility of sediments along the beach that results from 1) the action of longshore currents, between the emerged and submerged parts, and 2) the weather variations. Because it is fully inserted in the RMF, the coastal plain between the Porto das Dunas and Praia do Futuro beaches has suffered and continues to suffer the negative consequences of rapid urbanization and population growth. That, in turn, brings significant imbalances in the relationship between society and nature and engenders, as its most striking effect, environmental degradation. The grain size characteristics of this coastline are strongly conditioned by the influence of hydrodynamic, wind, and weather agents, associated with the type, orientation, and location of the beach as well as the proximity and type of sediment source area. It is recommended that future work conduct stratigraphic investigations along the coastal plain, detailed analyses of sediments on the morphoscopy and mineralogy, morphodynamic and sedimentological monitoring of the coastline, bathymetry and facies analyses of the shoreface and inner continental shelf adjacent, and previous studies (often covering medium and long periods) for building coastal resorts.

Keywords: Textural analysis; Seasonal variations; Morphodynamic beach.

\section{INTRODUÇÃO}

As praias arenosas oceânicas constituem um dos ambientes mais dinâmicos da superfície do planeta, cujos depósitos sedimentares são ativamente retrabalhados por ondas, correntes e marés (Short, 1999). Komar (1976) inclui, ainda, uma área litorânea abaixo do nível médio do mar (profundidades variando de $10 \mathrm{a} 20 \mathrm{~m}$ ), na qual as ondas de superfície exercem influência. Funcionam como importantes reservatórios de sedimentos, os quais são frequentemente alterados tanto pela ação marinha quanto pela antrópica.

As condiçóes ambientais de um sistema praial podem ser avaliadas pela análise e classificação dos sedimentos. Avaliar esse ambiente, em diferentes pontos de sua extensão requer a utilização de métodos de análises específicos na quantificação do resultado dos principais parâmetros ambientais e a escolha de pontos de amostragem representativos. A investigação dos processos sedimentares com base nas análises granulométricas vem sendo utilizada para a compreensão da dinâmica sazonal de ambientes sedimentares costeiros recentes.

A caracterização granulométrica é feita pela determinação das porcentagens em massa dos grãos, em cada classe granulométrica (fraçóes). Vários métodos têm sido utilizados para relacionar as classes granulométricas com o ambiente deposicional. Variaçóes de tamanho de grão ao longo da costa e transversalmente a ela são observadas em diversas praias em todo o mundo, sendo controlada por fatores geológicos (área-fonte), hidrodinâmicos e eólicos que atuam de forma distinta sobre os sedimentos. Estudos abordando a distribuição sedimentar ao longo das praias e fatores condicionantes foram feitos objetivando um melhor entendimento das condiçôes reinantes no momento de sua deposição e retrabalhamento, além de permitir traçar um fluxo da carga sedimentar.

A fonte do material e os processos de deposição afetam a distribuição do tamanho dos grãos dos sedimentos praiais, sendo que o elemento mais importante para a seleção do material da praia é a dissipação de energia das ondas, que é proporcional a sua altura (King, 1972). Desta forma, o material mais grosseiro está intimamente associado com zonas de maior energia.

Bascom (1951) sugere que o tamanho da partícula do sedimento e a intensidade da açáo das ondas controlam a inclinação da face praial. A açấo das ondas pode retirar partículas mais finas, as quais migrariam para a plataforma adjacente, fazendo com que os grãos mais grosseiros se acumulem na praia e, consequentemente aumentem a declividade. Este autor sugere ainda que a berma, juntamente com o degrau da praia são as zonas que apresentam os sedimentos mais grossos devido à ação da máxima excursão vertical do espraiamento da onda sobre a face de praia. Nordstrom (1981) conclui que o tamanho do grão náo varia com a altura da onda, sendo mais importante a fonte de sedimentos. Esta mesma teoria foi comprovada por Short (1999).

Bowen \& Inman (1966) sintetizaram as principais fontes e perdas de sedimentos existentes em um balanço sedimentar litorâneo (Tabela 1).

As praias pertencentes à planície costeira da Regiáo Metropolitana de Fortaleza (RMF), estado do Ceará, apresentam grande importância socioeconômica para a região, principalmente como áreas de turismo e lazer. As características morfodinâmica e sedimentar das praias, responsáveis pelo amortecimento da energia hidráulica, têm estimulado vários estudos que buscam um melhor conhecimento, objetivando a definição de estratégias para uma utilização racional/sustentável de seus recursos e preservação desses ambientes.

Este artigo tem como objetivo primordial caracterizar do ponto de vista granulométrico cinco praias arenosas (Porto das Dunas, Abreulândia - COFECO, Sabiaguaba, Caça e Pesca e Praia do Futuro em dois pontos) da RMF, promovendo o conhecimento integrado desses setores costeiros. 
Tabela 1. Balanço sedimentar litorâneo (adaptado de Bowen \& Inman, 1966).

Table 1. Littoral sedimenary budget (adapted from Bowen \& Inman, 1966).

\begin{tabular}{l|l|l}
\multicolumn{1}{c|}{ Fonte } & \multicolumn{1}{c|}{ Débito } & Balanço \\
\hline $\begin{array}{l}\text { Transporte de sedimentos por correntes ao longo da } \\
\text { costa para a praia }\end{array}$ & Transporte de sedimentos por correntes & $\begin{array}{l}\text { Deposição e erosão } \\
\text { praial }\end{array}$ \\
\hline Descarga Fluvial & $\begin{array}{l}\text { Transporte eólico para a formação de } \\
\text { dunas }\end{array}$ & \\
\hline Erosão de costóes & $\begin{array}{l}\text { Transporte de sedimentos para a } \\
\text { plataforma continental }\end{array}$ & \\
\hline Transporte de sedimentos da plataforma continental & & \\
\hline Transporte eólico para a praia & & \\
\hline Alimentação praial & & \\
\hline
\end{tabular}

\section{2. ÁREA DE ESTUDO}

A faixa litorânea estudada, localizada no litoral leste da Região Metropolitana de Fortaleza, estado do Ceará, possui uma extensão linear de $15 \mathrm{~km}$ e direção SE-NW (Figura 1).

Segundo Marino et al. (2012), a zona costeira da área pesquisada é representada por um empilhamento estratigráfico que compreende dois domínios geológicos: unidade basal e planície costeira. A unidade basal é constituída pela unidade litoestratigráfica Vulcânica-Alcalina, Terciária (Oligoceno-Mioceno), representada pelo morro Caruru; e pela Formação Barreiras, Tércio-Quaternária (MiocenoPleistoceno), constituída pelos sedimentos dos Tabuleiros Pré-Litorâneos. A planície costeira compreende Depósito aluvial (Quaternário/Pleistoceno); Depósitos litorâneos Arenito de praia (Quaternário/Plioceno), Fluviolacustre, Paludial, Eólico e Marinho praial do Holoceno (Figura 1).

O clima da RMF, segundo a classificação de Koppen, é do tipo tropical chuvoso (Aw'), apresentando uma forte irregularidade pluviométrica no decorrer do ano. As chuvas se concentram em cerca de $90 \%$ no primeiro semestre do ano, tendo seu ápice, para o período pesquisado, nos meses de abril de 2010 e março de $2011,350 \mathrm{~mm}$ e $670 \mathrm{~mm}$, respectivamente, com média anual variando de 1400$1600 \mathrm{~mm}^{1}$.

As águas superficiais da área abrangem parte de dois dos principais cursos fluviais formados pelos rios Pacoti e Cocó, que fazem parte da Bacia Metropolitana, definida pela SRH (Secretaria de Recursos Hídricos - Ceará, 2005). Esses rios têm suas nascentes em terrenos cristalinos. Segundo Ribeiro (2001), esses cursos de água estão classificados como intermitentes, com fluxo de escoamento no período chuvoso, esgotando parcialmente as lâminas d'água com o fim das precipitaçóes. De acordo com Molisani et al. (2006), a vazão fluvial média resultante para o estuário do rio Pacoti

1 - Veja-se o gráfico disponível no portal do Instituto Nacional de Meteorologia (INMET), em http://www.inmet.gov.br/sim/abre_Graficos.php?d ata $=05 / 2012 \&$ data $2=2011 \&$ lista $=11$, \&est $=82397 \& u f=C E$ foi calculada em 19 e $1 \mathrm{~m}^{3} / \mathrm{s}$, e para o estuário do rio Cocó foi estimada em 6 e $3 \mathrm{~m}^{3} / \mathrm{s}$, nos períodos de chuva e de estiagem, respectivamente.

$\mathrm{Na}$ configuração atual da faixa litorânea entre as praias Porto das Dunas e Praia do Futuro está sujeita à atuação de agentes dinâmicos que podem induzir mudanças em curto prazo, entre eles destacam-se as ondas e marés, as correntes e os ventos.

Os ventos alísios de SE e de NE são um dos agentes mais ativos no litoral da RMF, pois controlam a formação de correntes costeiras e ondas, além do transporte de sedimentos para a formação dos depósitos eólicos de toda a zona costeira pela deflação dos sedimentos do perfil praial. Segundo os dados da Fundação Cearense de Meteorologia - FUNCEME, no que diz respeito ao regime de ventos, de fevereiro a abril, possuem uma velocidade média de $3,7 \mathrm{~m} / \mathrm{s}$, procedentes de nordeste, com menores intensidades detectadas no mês de março. Morais (1980) relatou que a partir de maio ocorre uma intensificação gradativa dos ventos, atingindo valores máximos no mês de setembro com $7,2 \mathrm{~m} / \mathrm{s}$, e maior intensidade, com média de $6,8 \mathrm{~m} / \mathrm{s}$, no período de agosto a novembro.

Em relação às velocidades das correntes de vento na regiáo pesquisada, observa-se que seguem um padrão inverso ao pluviométrico, apresentando velocidades baixas na estaçáo de alta pluviosidade, meses de janeiro a junho, com leitura mínima de $0,09 \mathrm{~m} / \mathrm{s}$, enquanto na estaçáo de estiagem, meses de julho a dezembro, obtiveram-se as mais altas velocidades, registrando o valor máximo de $12,4 \mathrm{~m} / \mathrm{s}$ (Marino \& Freire, 2013).

A planície costeira encontra-se em contato direto com as águas do oceano Atlântico sul. As ondas que banham a área apresentam um forte componente de leste com direçóes variando entre os quadrantes E-NE e E-SE, mantendo uma estreita relação com as direções predominantes dos ventos, os quais são responsáveis pela configuração das dunas litorâneas pretéritas e atuais. Bensi (2006), referente à área metropolitana de Fortaleza, observou a dinâmica do transporte do sedimento costeiro e a morfologia do fundo marinho na porção de plataforma continental (Figura 2), na 


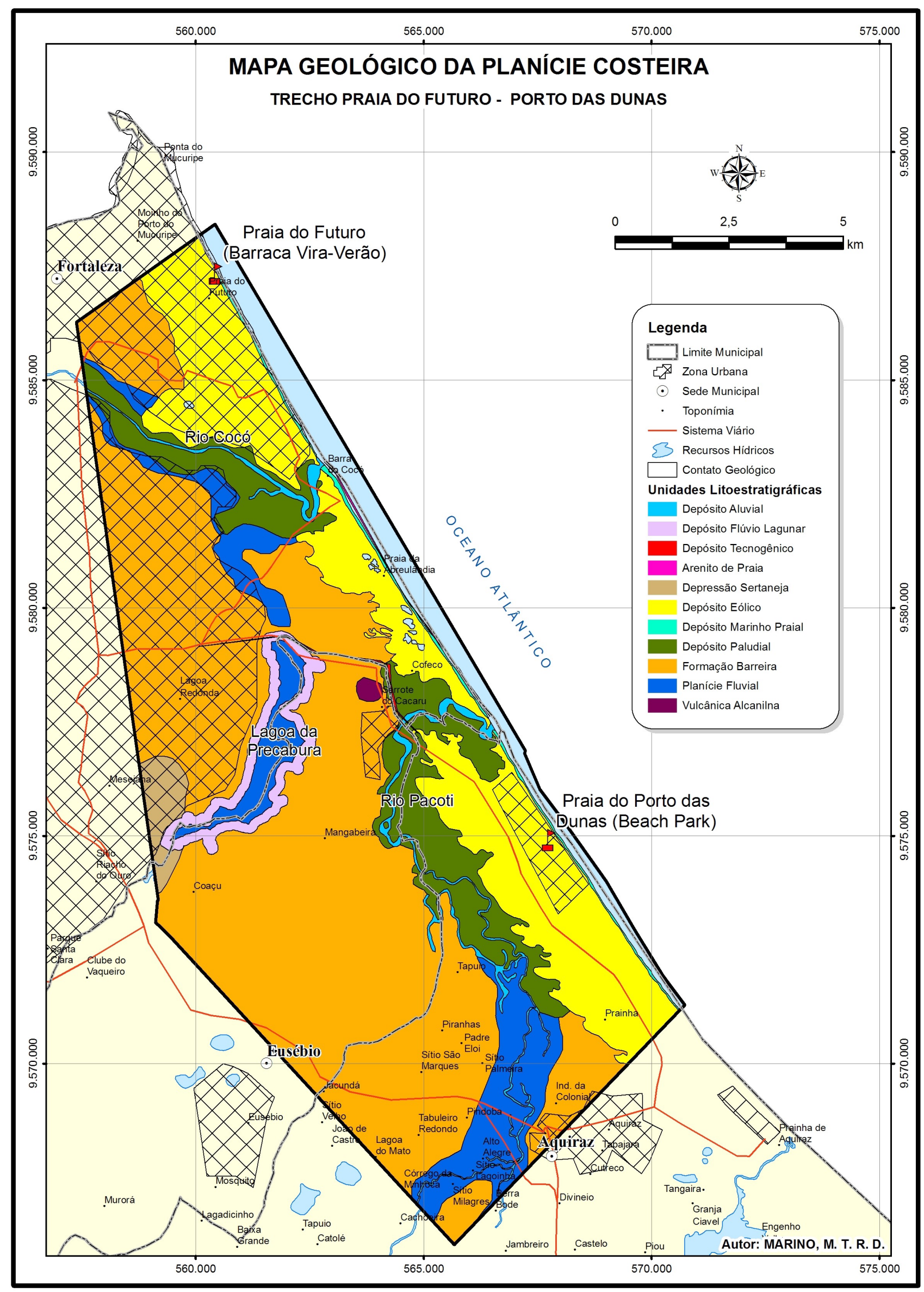

Figura 1. Mapa geológico e localização da área de estudo (segundo Marino et al., 2012). Figure 1. Geological and location map of the study area (accordingly to Marino et al., 2012). 
qual as setas vermelhas representam a direção das frentes de onda chegando ao litoral, e as setas brancas, de maneira geral, mostram a direção (SE-NW) da corrente de deriva, onde a faixa mais clara próxima ao litoral tem uma largura que varia entre 11 e $13 \mathrm{~km}$ e evidencia o transporte de material de fundo em suspensão devido às correntes de deriva litorânea, com batimetria variando de zero para $20 \mathrm{~m}$ de profundidade. As observaçóes de campo tomadas entre agosto de 2010 e agosto de 2011, mostraram que a altura significativa média das ondas variou de 1,6 a 2,9m, valor médio de $2,13 \mathrm{~m}$, com ondas incidindo obliquamente à costa, ângulo variando de $14^{\circ} \mathrm{NNE}$ a $344^{\circ} \mathrm{NE}$, provenientes preferencialmente de ESE.

\section{MATERIAL E MÉTODOS}

Para a caracterização da variação do tamanho do grão da área pesquisada foram coletadas 99 (noventa e nove) amostras de sedimentos, em 4 (quatro) etapas distribuídas sazonalmente, sendo uma no período de transição, uma no período de estiagem e duas no período chuvoso, entre agosto de 2010 e agosto de 2011. As coletas foram realizadas nos 6 (seis) pontos monitorados, durante a maré baixa de sizígia, em perfis transversais à costa, ao longo dos subambientes praiais ( pós-praia, estirâncio superior, estirâncio médio, estirâncio inferior e antepraia) e aos bancos e calhas longitudinais quando ocorrentes (Figura 3).

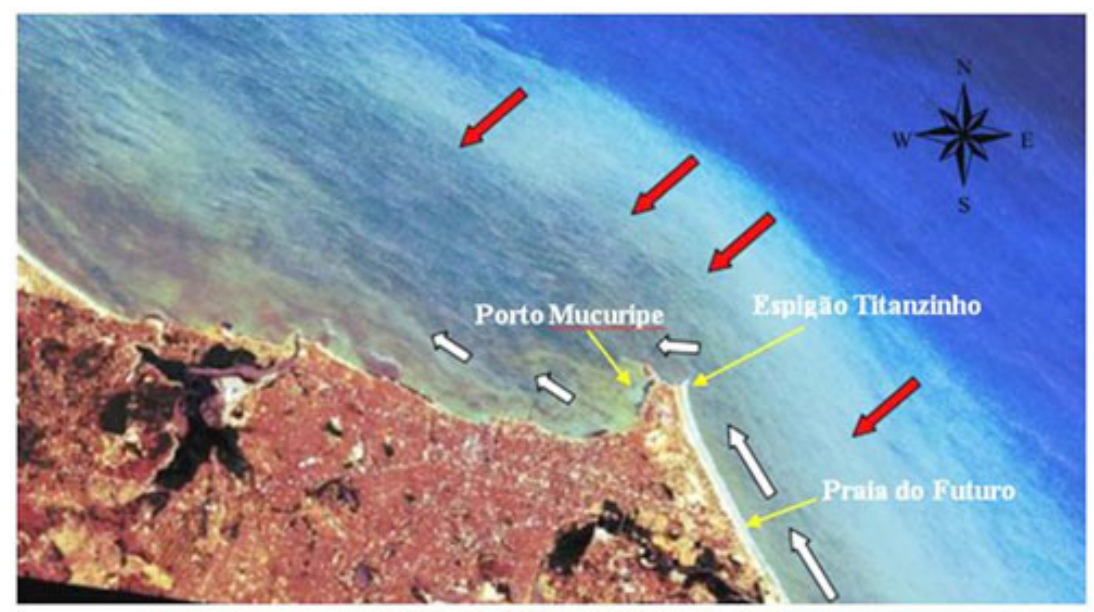

Figura 2. Mapa sobre imagem Landsat 7 ETM+ da Região Metropolitana de Fortaleza ressaltando a deriva litorânea dos sedimentos (segundo Bensi, 2006).

Figure 2. Map over Landsat 7 ETM + of Metropolitan Region of Fortaleza highlighting the littoral drift sediment (accordingly to Bensi, 2006).

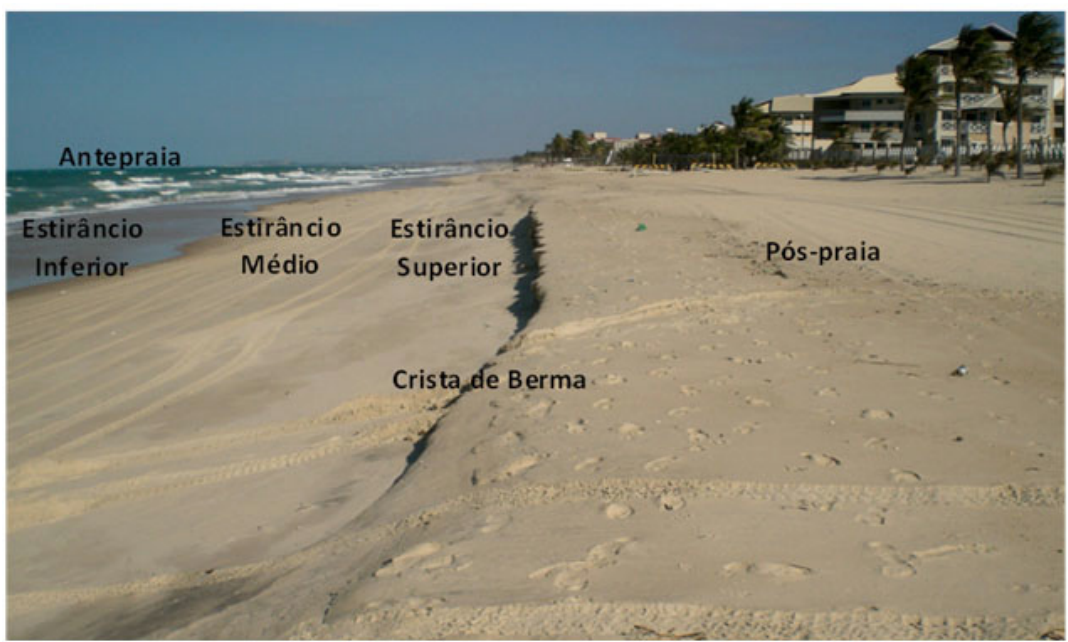

Figura 3. Perfil de praia transversal, praia de Porto das Dunas, Agosto de 2010. Figure 3. Beach cross-profile, Porto das Dunas Beach, August 2010. 
As amostras do estirâncio e pós-praia foram coletadas manualmente, em uma camada uniforme de $20 \mathrm{~cm}$ de sedimento, já da antepraia utilizou-se uma busca de fundo com draga do tipo "petit ponar". Todas as amostras foram acondicionadas em sacos plásticos, etiquetadas e transportadas ao Laboratório de Geologia Ambiental da Universidade de Fortaleza - UNIFOR, onde foram realizadas as análises sedimentológicas.

Em laboratório, as amostras de sedimento foram lavadas com água destilada para a retirada completa de sais solúveis e secas em estufa a uma temperatura aproximada de $60^{\circ} \mathrm{C}$. Após secas foram quarteadas para a obtenção de subamostras representativas. Aproximadamente $100 \mathrm{~g}$ foram utilizadas para a análise granulométrica dos sedimentos.

A fração de sedimentos grossos da amostra $(\geq 0,062 \mathrm{~mm})$ foi submetida ao processo de peneiramento mecânico por 20 minutos, já a fração fina $(<0,062 \mathrm{~mm})$ foi obtida por meio da diferença entre o total de amostras e o peso dos sedimentos grossos. Utilizou-se o método de peneiramento, baseado na escala granulométrica de Wentworth (1922, 1933) (mm) e Krumbein (1934) (Fi), cuja análise mecânica foi efetuada segundo intervalos de $1 / 4$ fi para maior fidelidade na expressão dos diferentes tamanhos de grão. A classificação preliminar dos sedimentos praiais, com base na frequência e no tamanho da partícula foi realizada através do digrama triangular de Shepard (1954).

Os dados obtidos das análises granulométricas foram tratados estatisticamente, utilizando-se as fórmulas de Folk \& Ward (1957), através da aplicação do software ANASED $5.0^{\circ}$ (Lima et al., 2001). Para todas as amostras foram calculados os parâmetros estatísticos: média, mediana, desvio padrão, assimetria e curtose.

Para um melhor embasamento dos resultados apresentados, criou-se um banco de dados com a sistematização das informaçóes e dados coletados em campo e gerados em laboratório por Marino \& Freire (2013), posteriormente conjugados com as metodologias de Dal Cin \& Simeoni (1994), Mallmann (2008), Mazzer (2007) e Castilhos (1995), efetuando-se uma análise preliminar para caracterizar os setores pesquisados quanto aos riscos e vulnerabilidade à erosão costeira, morfodinâmica, ocupação antrópica, extensão, entre outros (Tabela 2).

\section{RESULTADOS E DISCUSSĀO}

Os resultados são apresentados segundo os pontos monitorados, sazonalmente, nas cinco praias estudadas, no sentido de SE para NW, assim localizadas: praia Porto das Dunas (Aquaville Resort), praia da Abreulândia - COFECO, praia da Sabiaguaba, praia do Caça e Pesca e praia do Futuro (Hotel Vila Galé e Barraca Vira Verão). Esta subdivisão apoiou-se nas características geológicas e geomorfológicas do litoral, principalmente, nos aspectos distintivos das praias, levando-se, também em consideração as duas desembocaduras localizadas nesta faixa litorânea, a foz do rio Pacoti, localizada entre as praias Porto das Dunas e Abreulândia, e a foz do rio Cocó, entre as praias da Sabiaguaba e Caça e Pesca. Do ponto de vista cartográfico, possibilita a representação de três

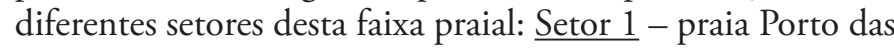
Dunas, entre o Condomínio Aquaville Resort e a margem direita do rio Pacoti; Setor 2 - praia da Abreulândia, entre as praias da COFECO e Sabiaguaba; e o Setor 3 - praia do Futuro, entre a praia do Caça e Pesca e o espigão da praia do Titanzinho - Porto do Mucuripe (Figura 4).

As propriedades texturais e parâmetros estatísticos das 99 amostras de sedimentos coletados nos 6 (seis) pontos monitorados, relativos ao período de agosto de 2010 a agosto de 2011, estão sumarizadas nas Tabelas 3, 4 e 5.

As figuras 5 e 6 apresentam uma visualização sazonal e comparativa dos pontos estudados, em um período de um ano.

\subsection{Setor 1 - Praia Porto das Dunas}

A análise granulométrica das amostras superficiais de sedimentos de praia permitiu constatar o predomínio da fraçáo arenosa ao longo dos cerca de 2,5 quilômetros de praia.

O tamanho médio dos grãos variou de areia fina a grossa, apresentando fácies textural predominante areia média, grau de seleção variando entre muito bem selecionado a pobremente selecionado, predominando a classe moderadamente selecionada, cuja assimetria apresenta-se bastante variada, desde negativa a muito positiva. A curtose variou de platicúrtica a muito leptocúrtica, predominando a classe mesocúrtica. Esses parâmetros indicam um ambiente de energia intermediária e certa normalidade na distribuição dos sedimentos, com material moderadamente selecionado, evidenciando que houve uma variação de energia moderada entre os períodos chuvoso, de transiçáo e estiagem.

Os sedimentos analisados e monitorados em frente ao Aquaville Resort (Ponto 1) apresentaram granulometria predominantemente média no estirâncio superior e estirâncio médio. Os sedimentos no estirâncio inferior e antepraia apresentaram características bimodais, a classe textural dominante foi areia grossa nos períodos de transição e estiagem. A areia média predominou no período chuvoso, com o surgimento de alguns sedimentos finos, o que pode ser esclarecido pela ocorrência de beachrocks submersos que dissipam a energia das ondas incidentes neste local, ou pela retirada dos grãos da regiâo de dunas frontais para a região da praia. Os sedimentos do pós-praia mantiveram uma granulometria constante ao longo do período estudado, que foi areia média. Quanto ao grau de seleção, $61,9 \%$ das amostras apresentaram-se moderadamente selecionadas e $28,57 \%$ bem selecionadas, corroborando com os dados anteriores.

Evidenciou-se um aumento no tamanho dos grãos na direção da desembocadura do rio Pacoti, localizado no limite oeste deste Setor, principalmente nos períodos de transição e estiagem. Este fato resulta da interaçâo de diversas variáveis, tais como: a maior dinâmica das ondas e ventos neste período que associada à descarga fluvial do rio Pacoti, resultou em um maior percentual de grossos; a influência de correntes de deriva litorânea no sentido SE-NW, o que ocasiona um melhor selecionamento das areias a leste; e o papel mitigador dos cordóes de beachrocks dispostos paralelamente à linha de costa atual (Figura 1). Esses cordões de beachrocks, em geral, não ultrapassam dois metros de largura e funcionam como anteparo natural para dissipaçáo da energia das 
ชั

$\dot{\hat{\Sigma}} \dot{0}$
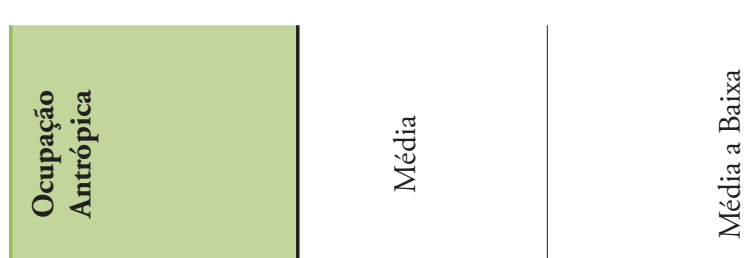

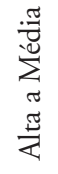

के शे

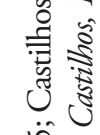

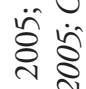

造

ஜे

\begin{tabular}{|c|c|c|c|}
\hline 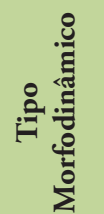 & 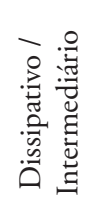 & 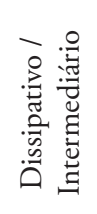 & 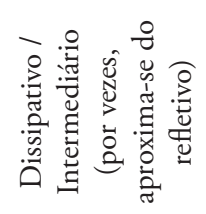 \\
\hline
\end{tabular}

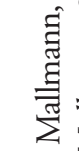

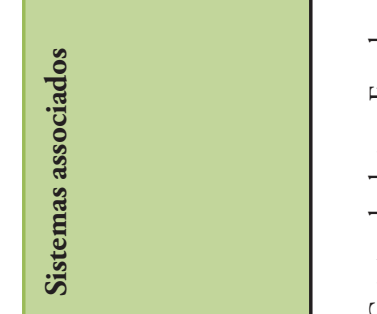

बूँ

茎

ปี

กี

हैं

产

离 恼

?

党

पः

क्षँّ

त्ञ

잔

氖 है

ฉั

तั है

हี

है

8 है

चे

ธั้

है है

है

总

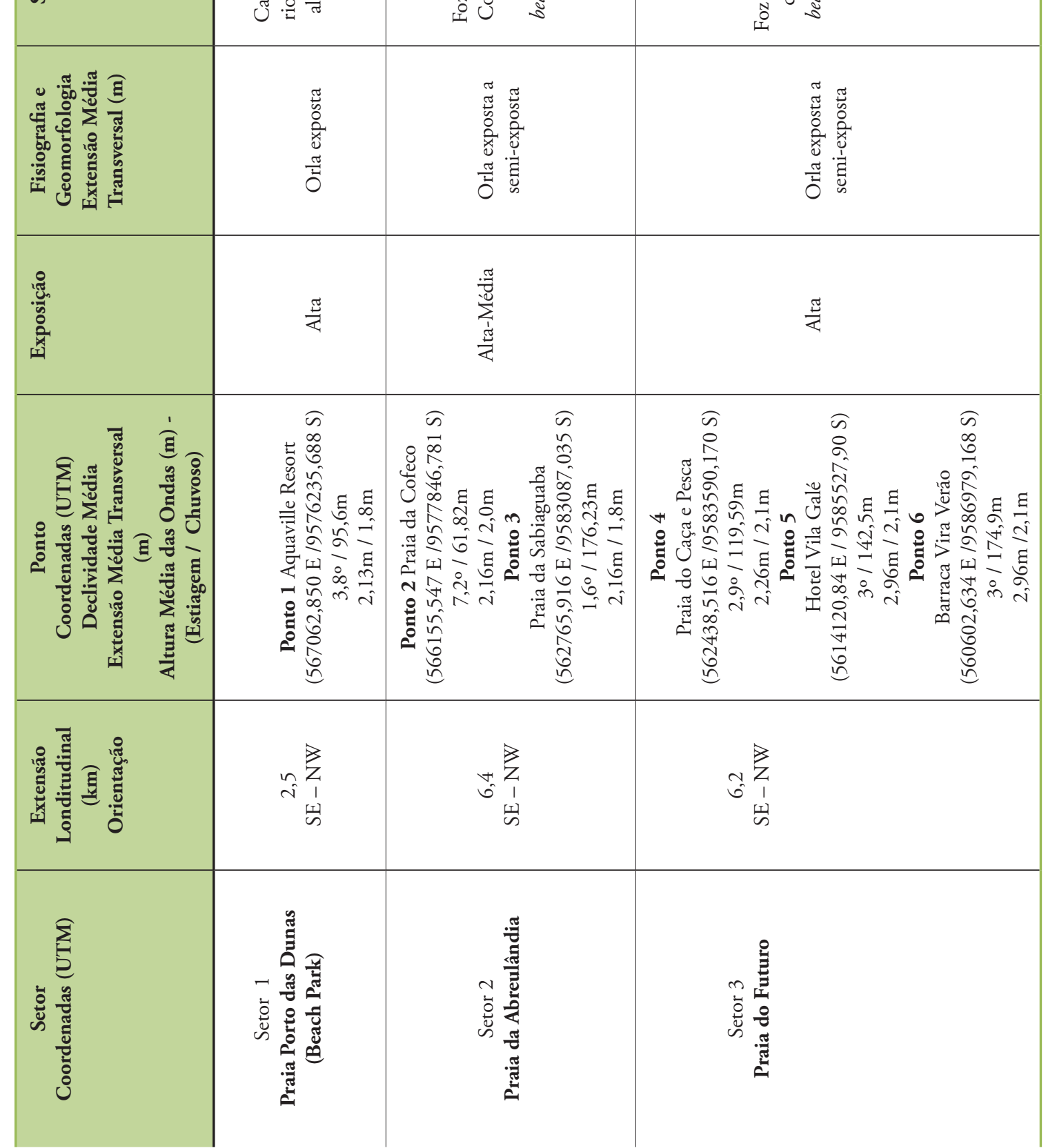




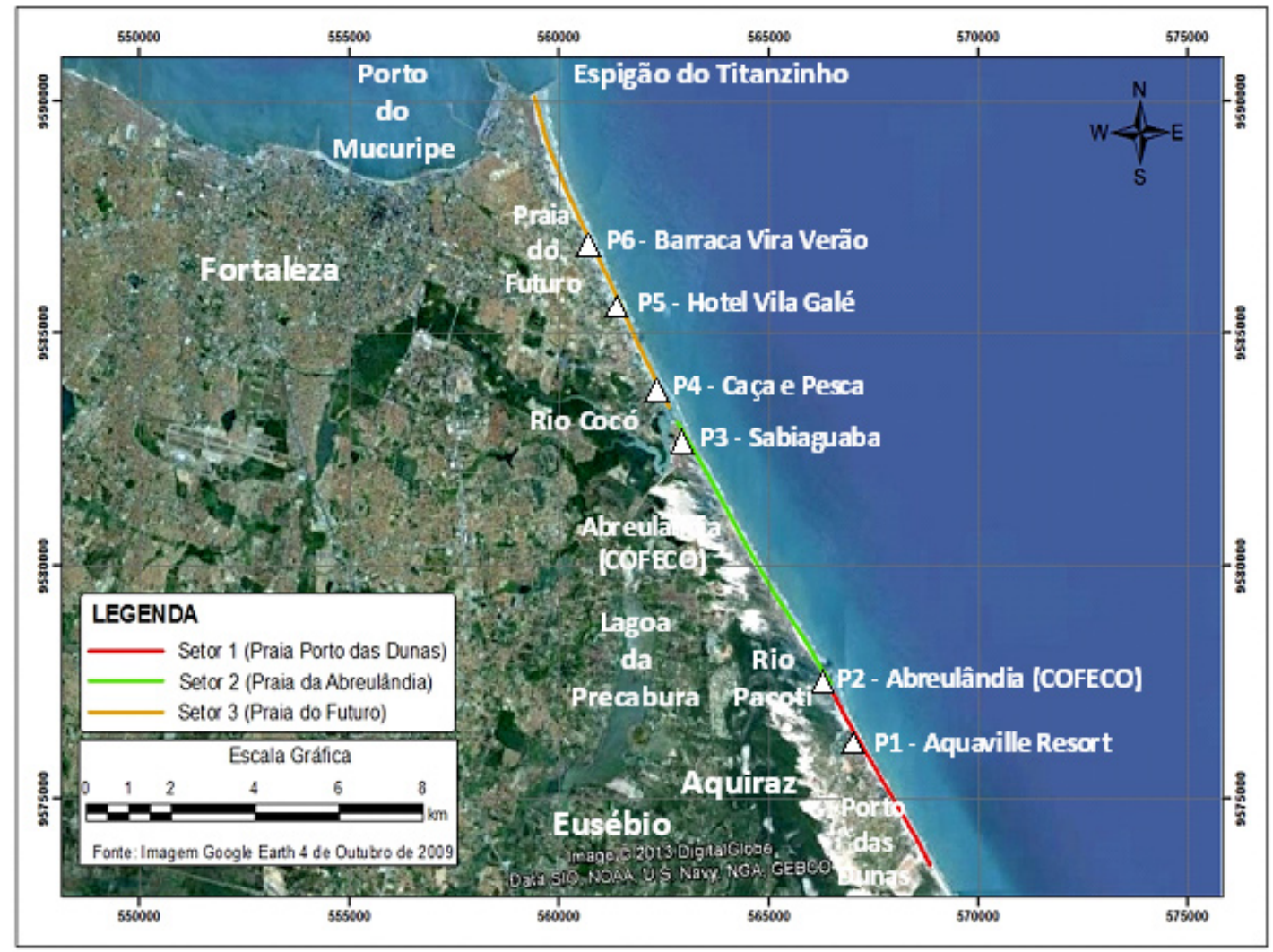

Figura 4. Localização dos pontos e compartimentação setorial da faixa litorânea do trecho Praia Porta das Dunas - Praia do Futuro (Imagem Google Earth, 2009).

Figure 4. Location of the points and sectorial subdivision of the coastal stretch of Porto das Dunas Beach - Praia do Futuro (Image Google Earth, 2009).

Tabela 3. Classificação geral da granulometria das praias arenosas da RMF, Ceará.

Table 3. Overall classification of grain size from the sandy beaches of RMF, Ceará.

\begin{tabular}{|c|c|c|c|c|c|c|c|c|c|c|c|c|}
\hline $\begin{array}{c}\text { Ponto/ } \\
\text { localizaçáo }\end{array}$ & A & AC & CA & $\mathrm{C}$ & Média & $\mathbf{M z}$ & C & AMG & AG & AM & AF & AMF \\
\hline $\begin{array}{l}\text { P1 - praia } \\
\text { Porto das } \\
\text { Dunas }\end{array}$ & 21 & - & - & - & 1,44 & $\mathrm{AM}$ & - & - & 5 & 14 & 2 & - \\
\hline $\begin{array}{c}\text { P2 - praia da } \\
\text { Abreulândia } \\
(\text { COFECO) }\end{array}$ & 16 & - & - & - & 0,91 & $\mathrm{AG}$ & - & - & 11 & 5 & - & - \\
\hline $\begin{array}{c}\text { P3 - praia da } \\
\text { Sabiaguaba }\end{array}$ & 15 & - & - & - & 1,15 & $\mathrm{AM}$ & - & - & 5 & 8 & 2 & - \\
\hline $\begin{array}{c}\text { P4 - praia do } \\
\text { Futuro (Caça e } \\
\text { Pesca) }\end{array}$ & 16 & - & - & - & 1,50 & $\mathrm{AM}$ & - & - & 7 & 6 & 3 & - \\
\hline $\begin{array}{c}\text { P5 - praia do } \\
\text { Futuro (Hotel } \\
\text { Vila Galé) }\end{array}$ & 15 & - & - & - & 1,87 & $\mathrm{AM}$ & - & - & 2 & 7 & 6 & - \\
\hline $\begin{array}{c}\text { P6 - praia } \\
\text { do Futuro } \\
\text { (Barraca Vira } \\
\text { Veráo) }\end{array}$ & 16 & - & - & - & 1,79 & $\mathrm{AM}$ & - & - & 1 & 8 & 7 & - \\
\hline
\end{tabular}

A - Número de amostras na classe textural areia; AC - Número de amostras na classe textural areia cascalhosa; CA - Número de amostras na classe textural cascalho arenoso; $\mathbf{C}-$ Número de amostras na classe textural cascalho; Diâmetro médio do grão (Mz), em $f$; Granulometria dominante (AMG - areia muito grossa; AG - areia grossa; AM - areia média; AF - areia fina; AMF - areia muito fina); C - Número de amostras na classe cascalho; AMG - Número de amostras na classe areia muito grossa; AG - Número de amostras na classe areia grossa; AM - Número de amostras na classe areia média; AF - Número de amostras na classe areia fina; AMF - Número de amostras na classe areia fina. 
Tabela 4. Classificação das praias arenosas da RMF quanto ao grau de selecionamento, assimetria e curtose.

Table 4. Classification of the sandy beaches of RMF in the sorting degree, skewness, and kurtosis.

\begin{tabular}{|c|c|c|c|c|c|c|c|c|c|c|c|c|c|c|c|c|c|}
\hline $\begin{array}{c}\text { Ponto/ } \\
\text { Localizaçáo }\end{array}$ & MBS & BS & MS & PS & MPS & EMS & MN & $\mathbf{N}$ & AS & $\mathbf{P}$ & MP & MP & $\mathbf{P}$ & $\mathbf{M}$ & L & ML & EL \\
\hline $\begin{array}{l}\text { P1 - praia } \\
\text { Porto das } \\
\text { Dunas }\end{array}$ & 1 & 6 & 13 & 1 & - & - & - & 2 & 6 & 8 & 5 & - & 2 & 13 & 5 & 1 & - \\
\hline $\begin{array}{c}\text { P2 - praia da } \\
\text { Abreulândia } \\
(\mathrm{COFECO})\end{array}$ & 4 & 2 & 9 & 1 & - & - & - & - & 5 & 10 & 1 & - & 1 & 5 & 5 & 5 & - \\
\hline $\begin{array}{l}\text { P3 - raia da } \\
\text { Sabiaguaba }\end{array}$ & 1 & - & 12 & 1 & 1 & - & - & 1 & 5 & 4 & 5 & - & 1 & 4 & 6 & 3 & 1 \\
\hline $\begin{array}{c}\text { P4 - praia do } \\
\text { Futuro (Caça } \\
\text { e Pesca) }\end{array}$ & 1 & 4 & 10 & 1 & - & - & 1 & 2 & 6 & 3 & 4 & - & 2 & 6 & 3 & 5 & - \\
\hline $\begin{array}{c}\text { P5 - praia } \\
\text { do Futuro } \\
\text { (Hotel Vila } \\
\text { Galé) }\end{array}$ & - & - & 14 & 1 & - & - & 2 & 2 & 5 & 5 & 1 & - & 4 & 5 & 4 & 2 & - \\
\hline $\begin{array}{c}\text { P6 - praia } \\
\text { do Futuro } \\
\text { (Barraca Vira } \\
\text { Veráo) }\end{array}$ & - & 2 & 14 & - & - & - & 1 & 3 & 6 & 3 & 3 & - & 4 & 9 & 2 & 1 & - \\
\hline
\end{tabular}

Classificação pelo grau de seleçáo: MBS (muito bem selecionado); BS (bem selecionado); MS (moderadamente selecionado); PS (pobremente selecionado); MPS (muito pobremente selecionado); EMS (extremamente mal selecionado); Classificaçăo pela assimetria: MN (muito negativa); $\mathbf{N}$ (negativa); $\mathbf{A S}$ (aproximadamente simétrica); P (positiva); MP (muito positiva); Classificação pela curtose: MP (muito platicúrtica); P (platicúrtica); M (mesocúrtica); L (leptocúrtica); ML (muito leptocúrtica); EL (extremamente leptocúrtica).

Tabela 5. Valores médios para o selecionamento, assimetria e curtose das praias arenosas da RMF. Table 5. Average values for sorting, skewness, and kurtosis of the sandy beaches of RMF.

\begin{tabular}{|c|c|c|c|c|c|c|c|c|}
\hline Ponto/localizaçáo & $\begin{array}{c}\mathrm{Dp} \\
\text { médio }\end{array}$ & Seleção & Ski > & Ski > & Ski $<$ & Ski < & Kg médio & Curtose \\
\hline $\begin{array}{c}\text { P1 - praia Porto } \\
\text { das Dunas }\end{array}$ & 0,63 & MS & 0,44 & MP & $-0,19$ & $\mathrm{~N}$ & 1,03 & M \\
\hline $\begin{array}{l}\text { P2 - praia da } \\
\text { Abreulândia } \\
(\mathrm{COFECO})\end{array}$ & 0,51 & MS & 0,29 & $\mathrm{P}$ & $-0,08$ & AS & 1,53 & ML \\
\hline $\begin{array}{c}\text { P3 - praia da } \\
\text { Sabiaguaba }\end{array}$ & 0,62 & MS & 0,57 & MP & $-0,21$ & $\mathrm{~N}$ & 1,09 & $\mathrm{M}$ \\
\hline $\begin{array}{c}\text { P4 - praia do } \\
\text { Futuro (Caça e } \\
\text { Pesca) }\end{array}$ & 0,61 & MS & 0,42 & MP & $-0,41$ & $\mathrm{MN}$ & 1,29 & $\mathrm{~L}$ \\
\hline $\begin{array}{l}\text { P5 - praia do } \\
\text { Futuro (Hotel } \\
\text { Vila Galé) }\end{array}$ & 0,73 & MS & 0,30 & MP & $-0,58$ & $\mathrm{MN}$ & 1,07 & $M$ \\
\hline $\begin{array}{c}\text { P6 - praia do } \\
\text { Futuro (Barraca } \\
\text { Vira Veráo) }\end{array}$ & 0,65 & MS & 0,48 & MP & $-0,43$ & $\mathrm{MN}$ & 1,03 & M \\
\hline
\end{tabular}

Dp Médio - valor médio do desvio padrão (em fi); Seleçáo - Classificação média do desvio padrão (MBS - muito bem selecionado; BS - bem selecionado; MS - moderadamente selecionado; PS - pobremente selecionado; MPS - muito pobremente selecionado; EMS - extremamente mal selecionado); Ski> - Máximo valor de assimetria e classificação; $\mathbf{S k i}<$ - Mínimo valor de assimetria e classificação (MN - muito negativa; $\mathbf{N}$ - negativa; AS - aproximadamente simétrica; $\mathbf{P}$ - positiva; MP - muito positiva); Kg médio - valor médio da curtose; Curtose - Classificação média da curtose (MP - muito platicúrtica; $\mathbf{P}$ - platicúrtica; $\mathbf{M}$ - mesocúrtica; L - leptocúrtica; $\mathbf{M L}$ - muito leptocúrtica; EL - extremamente leptocúrtica). 


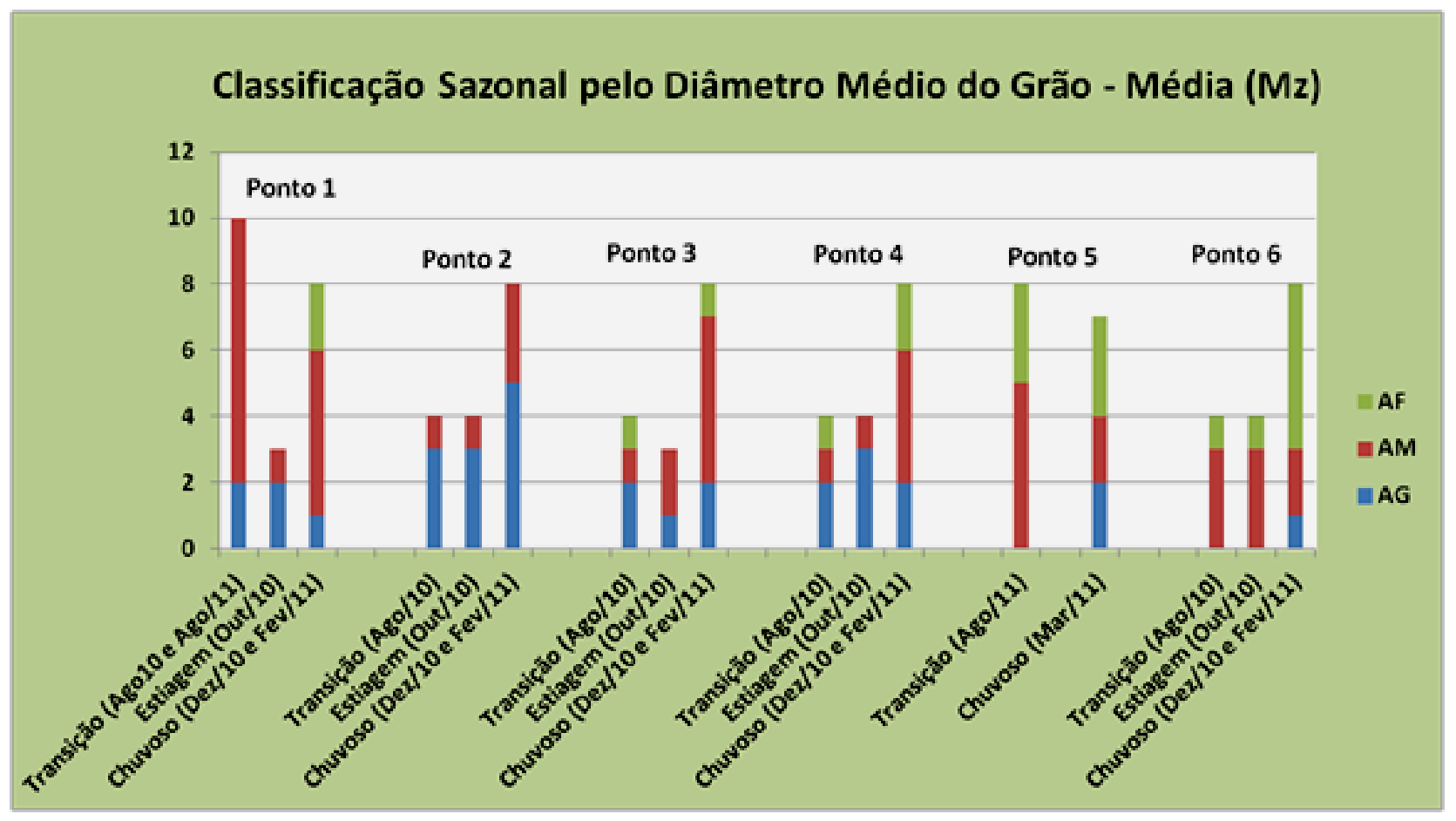

Figura 5. Classificação sazonal pelo diâmetro médio do grão para as praias monitoradas.

Figure 5. The seasonal rating by average diameter grain to the beaches monitored.

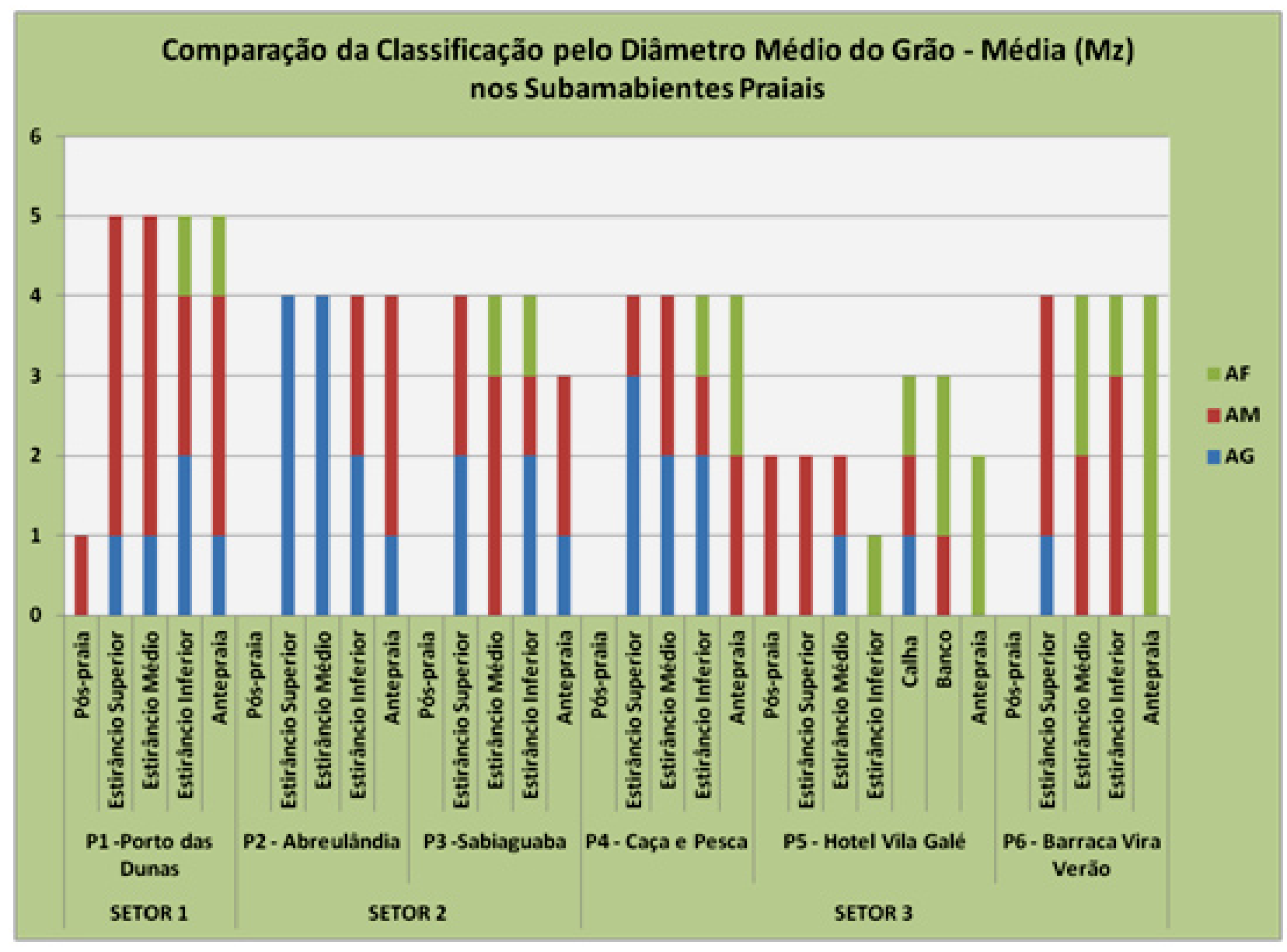

Figura 6. Comparação da distribuição das classes granulométricas nos diferentes setores e subambientes praiais. Figure 6. Distribution of grain size fractions in different sectors and beach sub-environments 
ondas, protegendo as praias da erosão. Sua litologia varia de conglomerado a arenito grosso a muito grosso, refletindo a presença de maior energia em momento anterior a cimentação e, por vezes apresentam seixos e fragmentos de conchas (Figura 7 e 8).

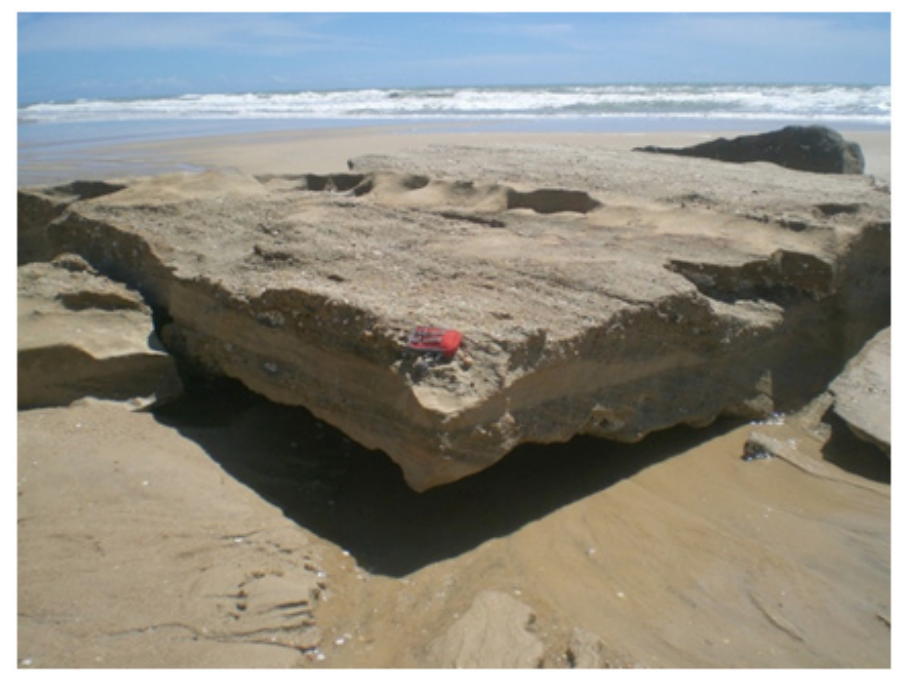

Figura 7. Afloramento de arenito de praia. Praia Porto das Dunas (Ponto 1), período de transição (Agosto de 2011). Figure 7. Beachrock outcrop. Porto das Dunas Beach (Point 1), transition season (August 2011).

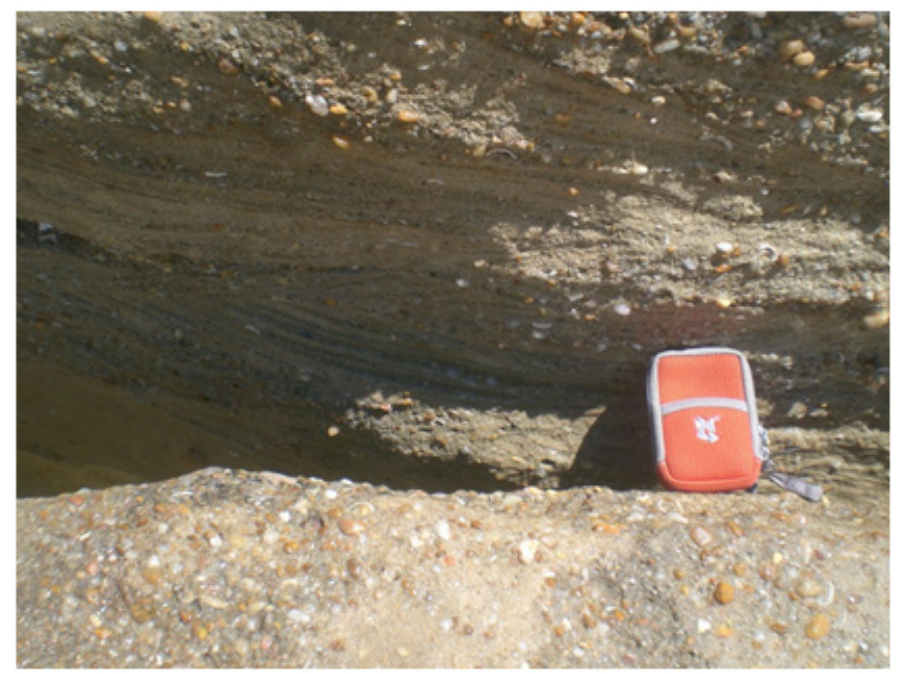

Figura 8. Detalhe da textura e estruturas (estratificação cruzada acanalada e plano paralela) do arenito de praia. Praia Porto das Dunas (Ponto 1), período de transição (Agosto de 2011).

Figure 8. Detail texture and structures (trough cross-stratifications and horizontal stratification) beachroks). Porto das Dunas Beach (Point 1), transition season (August 2011).

Segundo a classificação de Wright \& Short (1984) praias caracterizadas por sedimentos de granulometria bimodal, comumentesão enquadradas emintermediárias, apresentando uma maior mobilidade e uma maior variabilidade sedimentar segundo as classificaçóes morfodinâmicas existentes, neste Setor variando de dissipativa a intermediária, vide Tabela 2.

Comparativamente, os resultados encontrados mostram que houve uma alteração nos parâmetros estatísticos entre os períodos de transição e estiagem, em relação ao período chuvoso. Nos dois primeiros períodos foram registrados ventos mais fortes, ondas com alturas mais significativas e, consequentemente perfis de inverno com formaçáo de calhas (canais) e bancos longitudinais, que funcionam como armadilhas de sedimentos de granulometria variando de média a fina (Figura 3, 5, 6 e 9). Já no período chuvoso foi registrada uma grande acumulaçáo de areia no perfil praial subaéreo, registrando uma declividade mais suave, acumulação de sedimentos mais finos no meio aquoso, conforme amostras analisadas (Figura 5, 6 e 10).

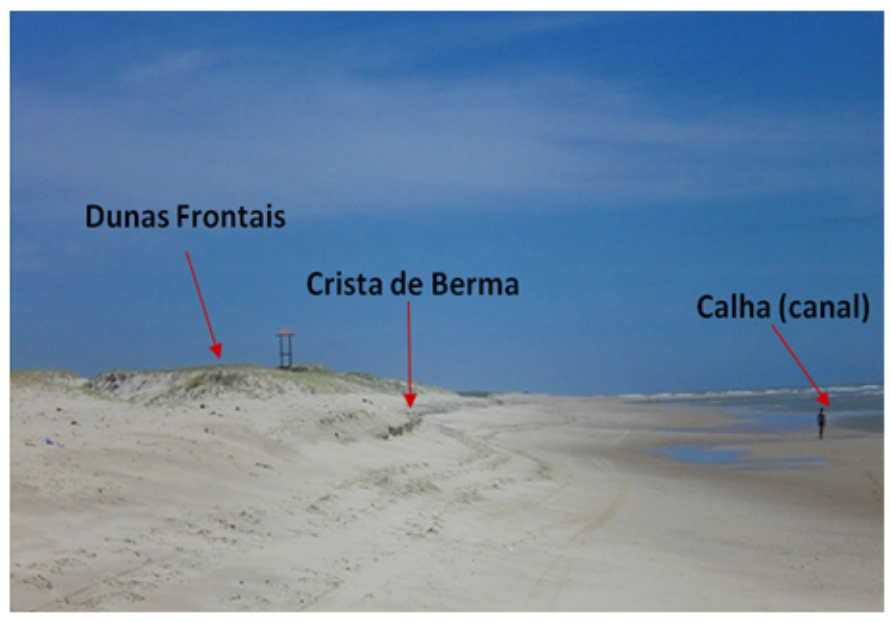

Figura 9. Praia Porto das Dunas (Ponto 1), perfil de inverno, período de transição (Agosto de 2011).

Figure 9. Porto das Dunas Beach (Point 1), rainy profile, transition season (August 2011).

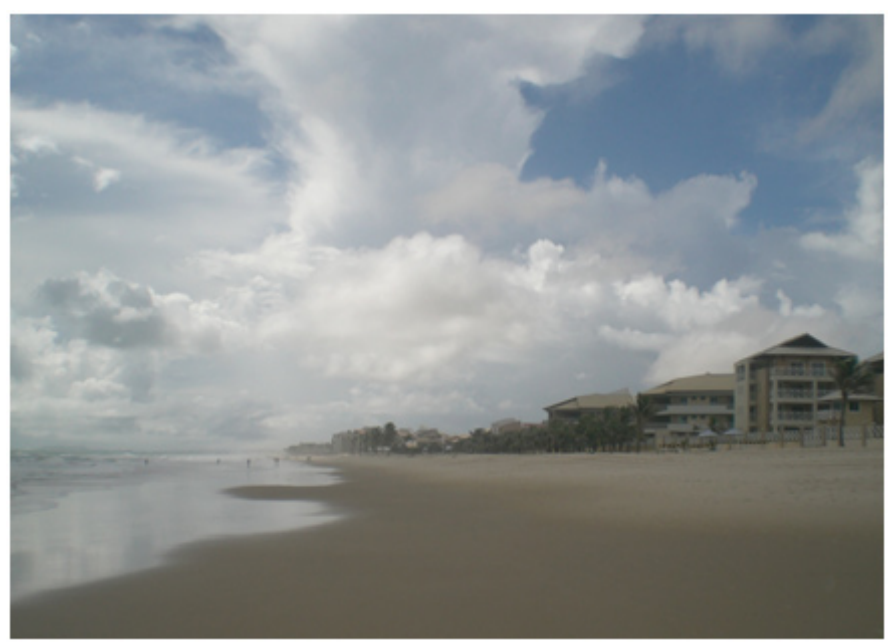

Figura 10. Praia Porto das Dunas (Ponto 1), perfil de verão, período chuvoso (Fevereiro de 2011).

Figure 10. Porto das Dunas Beach (Point 1), summer profile, rainy season (February 2011). 


\subsection{Setor 2 - Praia da Abreulândia}

O Setor 2 se destaca por apresentar fácies granulométrica variando de areia média a areia grossa, predominantemente, associada à mistura das areias médias dos campos de dunas e bancos de areia que assoreiam os rios Pacoti e Cocó e são transportados até a faixa praial, bem como pela contribuição dos sedimentos grossos que são desagregados dos arenitos de praia (beachrocks) pelos processos de intemperismo e erosão, ocorrendo paralelos à faixa praial e associados à foz dos rios supracitados (Figura 11 e 12). Ressalta-se ainda a contribuição dos sedimentos da Formação Barreiras (Tabuleiros Pré-litorâneos), os quais apresentam geralmente areia grossa a média, são transportados pelo fluxo hidráulico até a desembocadura dos rios, principalmente no período chuvoso, e distribuídos pela corrente de deriva litorânea ao longo da costa no sentido SE-NW.

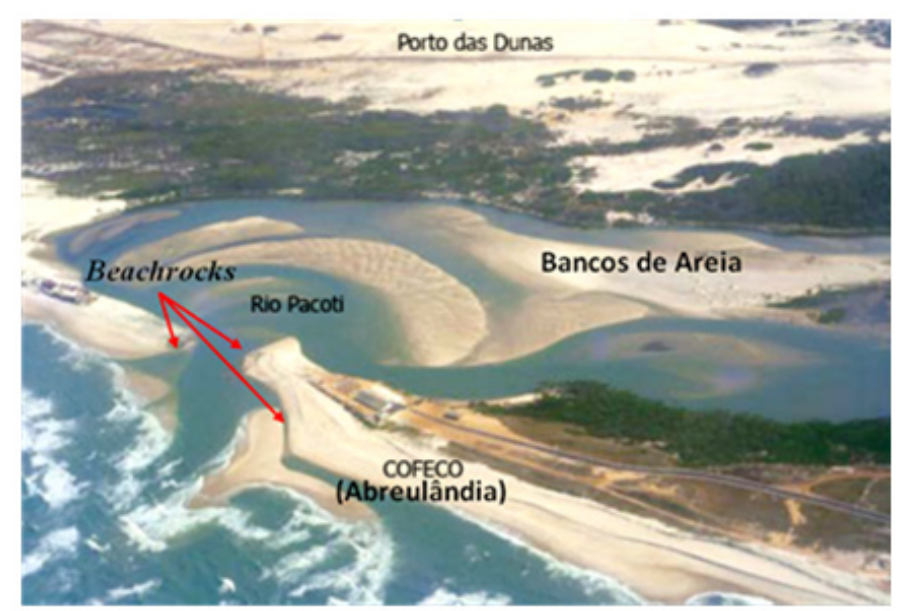

Figura11. Desembocadura do rio Pacoti (Meireles \& Maia, 2003).

Figure 11.Pacoti River mouth (Meireles and Maia, 2003).

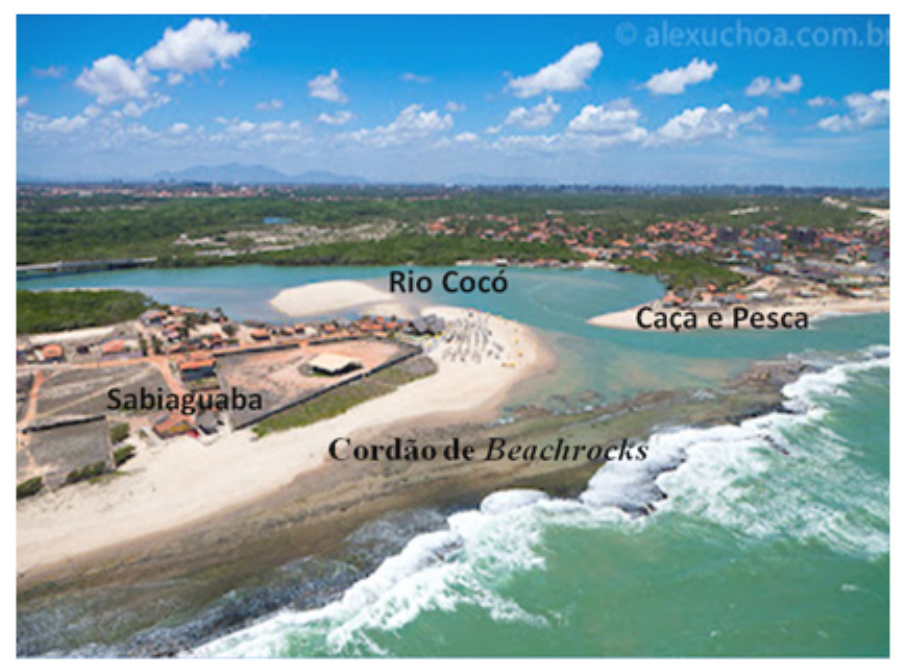

Figura 12. Desembocadura do rio Cocó (Galeria Alex Uchoa net, 2013).

Figure 12. Coco River mouth (Alex Uchoa Galery - net, 3013).
A praia da Abreulândia - COFECO (Ponto 2), localizada à margem esquerda do rio Pacoti, apresentou variação do tamanho médio dos grãos de areia média a grossa, predominando areia grossa, com curtose variando desde platicúrtica até muito leptocúrtica, indicando variações nas condiçóes energéticas do ambiente e uma bimodalidade dos sedimentos, característica de ambientes de transição. Verificou-se uma variação do grau de assimetria de aproximadamente simétrica a muito positiva, registrando uma mudança nos estágios de deposição dos sedimentos. Entretanto, a assimetria muito positiva indica acumulaçáo de sedimentos em áreas protegidas, corroborando com a presença dos bancos de areia no canal do rio Pacoti, e uma grande quantidade de areia média retida e assoreando o ecossistema manguezal próximo à foz (Figura 11 e 13).

Nas estaçóes de estiagem e de transição os sedimentos analisados apresentaram um melhor selecionamento, havendo, portanto uma maior influência da energia das ondas. Ao contrário na estação chuvosa foi observada a predominância de sedimentos moderadamente selecionados em quase todo ambiente. Apenas duas amostras foram classificadas como bem selecionadas, uma na antepraia e outra no estirâncio médio. Assim, no inverno não houve um ambiente de energia suficiente para um bom selecionamento dos grãos, como observado nas estaçóes de estiagem e transição (Figura 13).

Na praia da Sabiaguaba (Ponto 3), à margem direita do rio Cocó, a classe textural varia de areia grossa a areia fina, predominando areia média, com grau de seleçâo bastante diversificado, mas com uma forte predominância de sedimentos moderadamente selecionados. A curtose indicou bimodalidade do material, variando de platicúrtica a extremamente leptocúrtica, enquanto a assimetria mostrou-se bastante diversificada, passando de negativa a muito positiva, sugerindo que ocorreu variação de energia e mudança de estágio de erosão para acumulação de sedimentos. Este fato está fortemente relacionado à sazonalidade da região, caracterizada por um período chuvoso, no primeiro semestre, e outro de estiagem, no segundo semestre. Esta sazonalidade também influencia na morfologia dos perfis praiais, apresentando perfis de inverno nos períodos de transição e estiagem, o perfil torna-se mais íngreme junto à antepraia, devido a existências de ondas de tempestade causadas por ventos intensos. A praia emersa vê o seu perfil rebaixado por erosão, ocorre formação da berma (escarpa) e os sedimentos resultantes desse processo são depositados nas áreas imersas, com bancos e calhas longitudinais associados. Já no período chuvoso a ausência de ondas de tempestade e ventos mais amenos contribui para a formação de perfis de verão com inclinação mais suave.

No Ponto 3, durante o período chuvoso observa-se uma predominância dos sedimentos mais grossos nas áreas mais afastadas da linha de costa (estirâncio superior), e os mais finos na região subaquosa, ocorrendo uma inversão no período de estiagem (Figura 5). Esse processo pode ser explicado pelas ressacas que ocorrem durante esse período chuvoso, removendo os grãos menores e deixando os maiores e mais difíceis de carregar. O campo de dunas contribui fortemente para o equilíbrio da faixa de praia, observandose, ainda, uma expressiva formação de dunas frontais no póspraia (Figura 14). 
Nuber et al. (2006) discutiram que, mudanças na distribuição dos sedimentos e elevação do perfil, principalmente no pós-praia, são produzidos pela migraçáo da zona de espraiamento onde a berma é caracterizada por sedimentos de baixo grau de selecionamento.

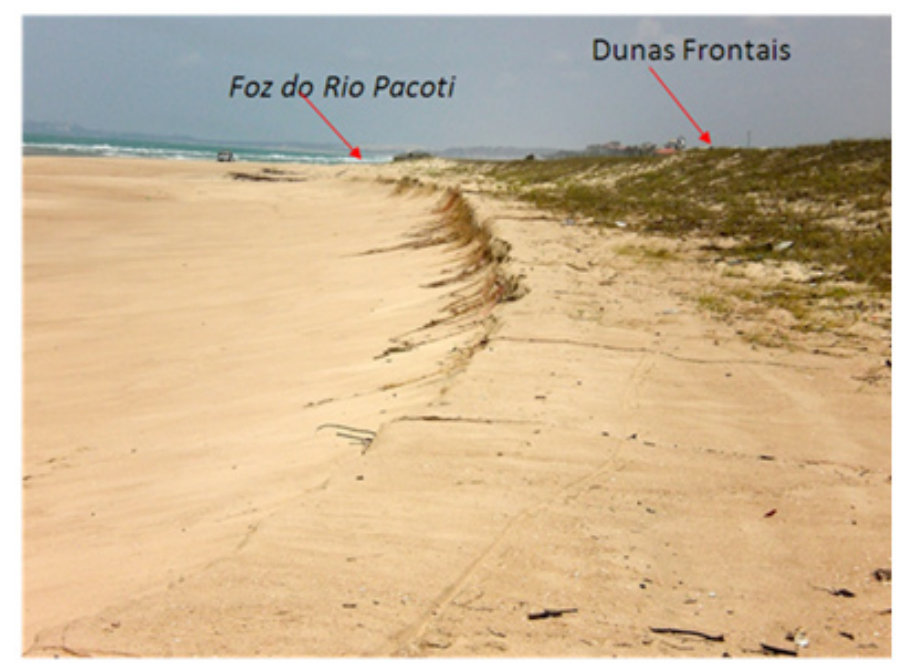

Figura 13 Praia da Abreulândia - COFECO (Ponto 2), período de estiagem (Outubro de 2010).

Figure 13. Abreulândia Beach - COFECO (Point 2), dry season (October 2010).

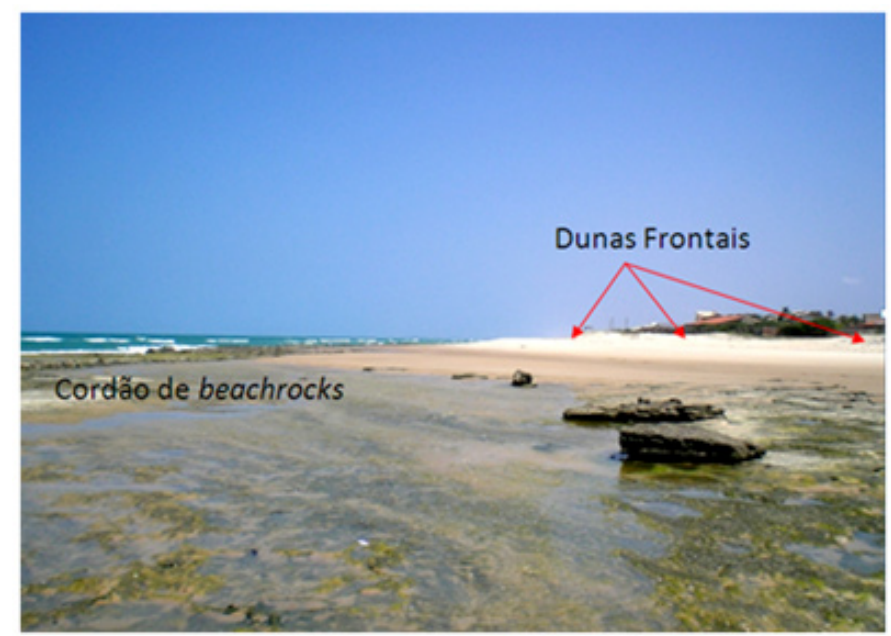

Figura 14. Praia da Sabiaguaba (Ponto 3), período de estiagem (Outubro de 2010).

Figure 14. Sabiaguaba Beach (Point 3), dry season (October 2010).

\subsection{Setor 3 - Praia do Futuro}

Para uma melhor caracterização da interação das populaçóes sedimentares nos diferentes subambientes da praia do Futuro, a localidade foi analisada em três pontos, os quais apresentam características sedimentológicas distintas (Figura 5 e 6 ).

Os sedimentos da praia do Caça e Pesca (Ponto 4) apresentaram o tamanho médio dos grãos variando de areia fina a areia grossa, com predomínio desta última, e a seleção de muito bem selecionada a pobremente selecionada. Os sedimentos apresentaram maior diâmetro em comparaçáo aos outros dois pontos deste Setor, devido à erosão e intemperismo dos cordóes de arenitos de praia que ocorrem associados às desembocaduras dos rios Pacoti e Cocó e funcionam como uma barreira para a energia das ondas. A curtose é bastante variável, desde platicúrtica a muito leptocúrtica, e a assimetria passou de muito negativa a muito positiva, indicando que os sedimentos são bimodais, havendo variação das condições energéticas, inicialmente com deposiçáo e posteriormente remoção do material fino.

No Ponto 5, em frente ao hotel Vila Galé, a granulometria apresentou variação de areia grossa a fina, predominando a classe textural areia média, com grau de seleção variando de moderadamente selecionado a pobremente selecionado. A curtose passou de platicúrtica a muito leptocúrtica, sugerindo a ocorrência de variação nas condiçóes de energia, uma vez que o material apresenta bimodalidade, com assimetria muito negativa a muito positiva, ou seja, passou de um estágio de erosão para deposição de material fino, fato relacionado às variaçôes sazonais dos perfis praiais, perfil de inverno e perfil de verão, durante o período monitorado.

$\mathrm{Na}$ Barraca Vira Verão (Ponto 6) os sedimentos variaram de areia grossa a areia fina, com predominância de areia fina, ressaltando uma quantidade maior de sedimentos finos em relação aos pontos anteriores. $\mathrm{O}$ grau de seleção variou de bem selecionado a moderadamente selecionado, predominando este último, cuja curtose apresenta-se bastante diversa, desde platicúrtica a muito leptocúrtica, e um grau de assimetria entre muito negativa a muito positiva, mais uma vez demonstrando que ocorreu variação nas condiçóes energéticas do ambiente e sugerindo uma mudança nos estágios de remoção e deposição dos sedimentos finos.

Os sedimentos do estirâncio inferior, neste Setor, apresentaram características polimodais, o que sugere uma grande alternância nos níveis de energia.

Em toda extensão dessa área foi observada a formação de bancos e calhas longitudinais. Os bancos arenosos são caracterizados, predominantemente, por sedimentos de granulometria fina, moderadamente selecionados, podendo variar a média no período de transição. As calhas apresentaram sedimentos grossos no período chuvoso e textura fina a média no período de transição, aumentando o tamanho do grão em direção à costa. Segundo Sonu (1972), o principal mecanismo de controle de mudanças do perfil praial está relacionado ao comportamento desses bancos sobre a superfície subaérea da praia.

Grande parte do movimento de material ocorre entre os bancos de areia e a berma. Estes bancos são produtos de erosão, pois a ação violenta das ondas corta a parte anterior da berma e deposita tal material a certa distância da costa. Os bancos se formam em condições tempestuosas, portanto, características do perfil de inverno. Entretanto neste Setor, a baixa declividade $\left(3^{\circ}\right)$ favorece a formação de um número maior de calhas e bancos longitudinais, comuns nos períodos monitorados (Figura 15 e 16).

Durante o período de estiagem, as variaçóes no padrão de energia são menores, em geral ocorre uma inversão na distribuição dos sedimentos, os sedimentos grossos e médios predominam na regiáo subaquosa e as fraçôes médias e finas 
na zona de espraiamento, o que proporciona uma acrescáo de sedimentos no perfil subaéreo.

Este Setor apresenta característica intermediária a dissipativa e intenso transporte eólico agindo na população de sedimentos finos a médios na região de espraiamento, o que denota significativas acumulaçóes de sedimentos na regiâo do pós-praia, formando dunas frontais.

Observa-se uma tendência à diminuição do tamanho médio do grão na direção NW, o que pode ser explicado pelo distanciamento das desembocaduras dos rios Pacoti e Cocó, os quais têm associados os sedimentos de textura mais grossa das faixas descontínuas de arenitos de praia (Figura 17).

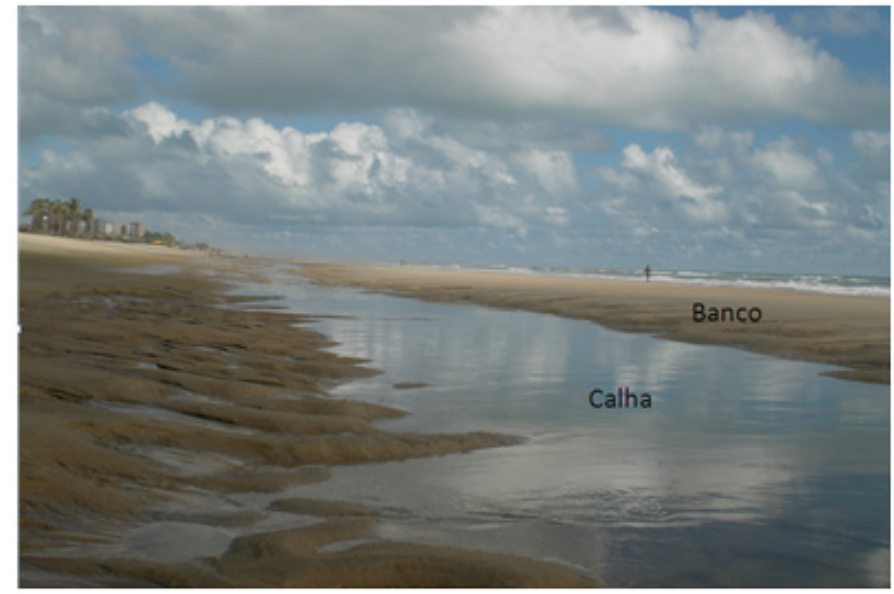

Figura 15. Praia do Futuro - Hotel Vila Galé (Ponto 5), período chuvoso (Março de 2011).

Figure 15. Praia do Futuro Beach - Vila Galé Hotel (Point 5), rainy season (March 2011).

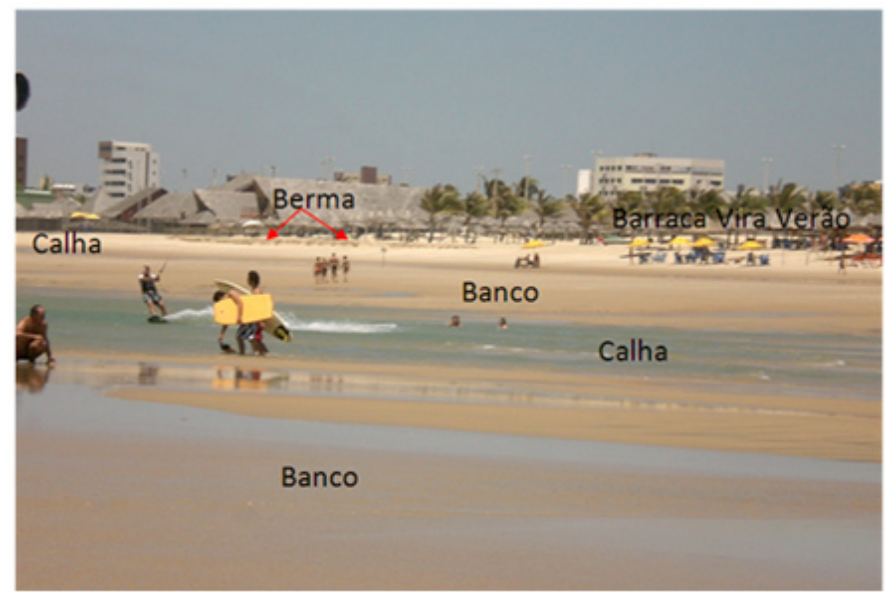

Figura 16. Praia do Futuro - Barraca Vira Verão (Ponto 6), período de transiçáo (Agosto de 2010).

Figure 16. Praia do Futuro Beach - Vira Verão Shack (Point 6), transition season (August 2010).

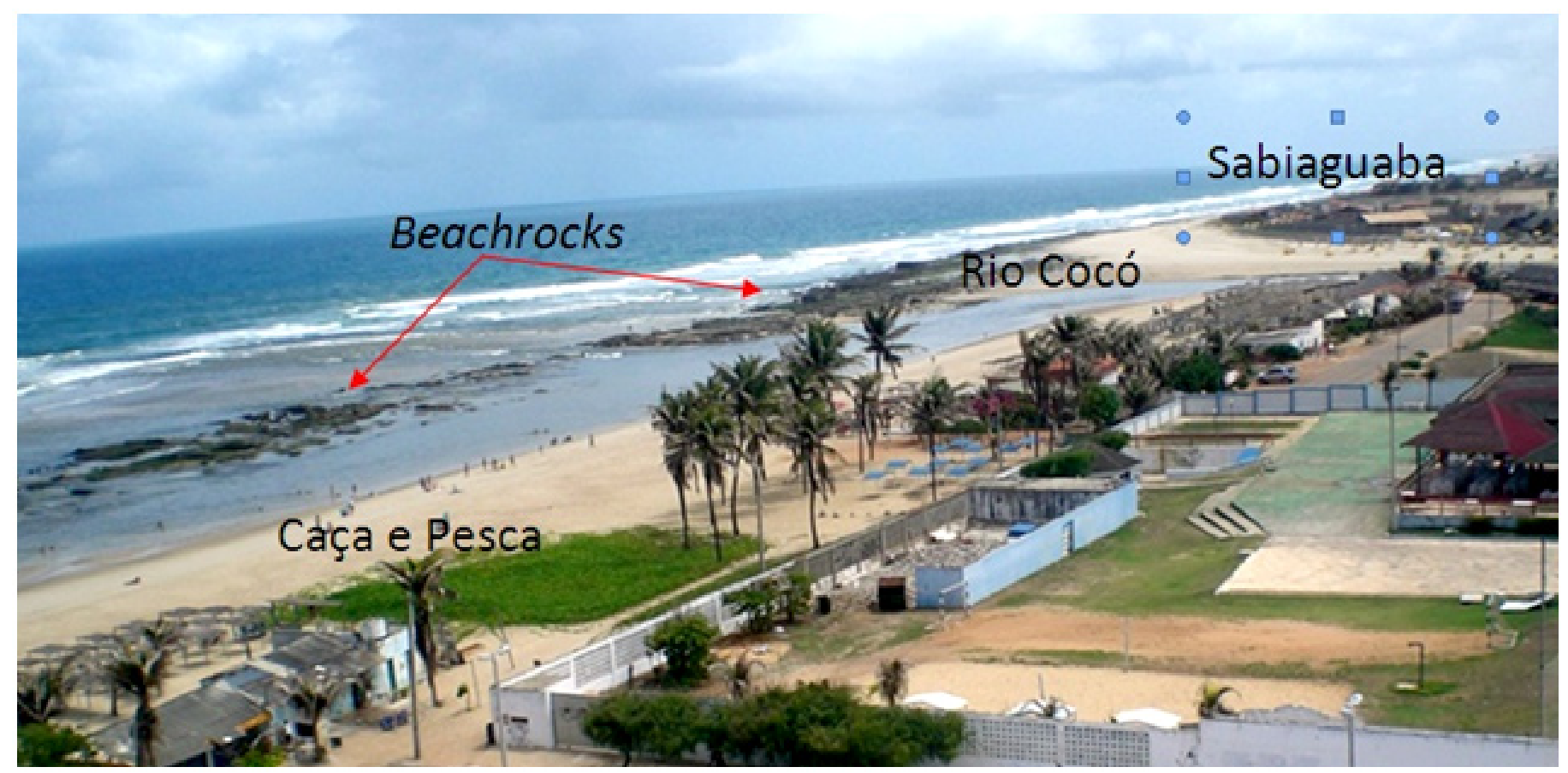

Figura 17. Praia da Sabiaguaba (Ponto 3) e Praia do Caça e Pesca (Ponto 4), margens da desembocadura do rio Cocó, período chuvoso (Dezembro de 2010).

Figure 17. Sabiaguaba Beach (Point 3) and Caça e Pesca Beach (Point 4), the margins of the Coco River mouth, rainy season (December 2010). 


\section{CONSIDERAÇÓES FINAIS}

A análise granulométrica das 99 amostras superficiais de sedimentos de praia permitiu constatar o predomínio da fração arenosa ao longo dos cerca de 15 quilômetros de praia.

Os sedimentos são predominantemente compostos de areia média, moderadamente selecionada, entretanto granulaçóes mais finas ocorrem nas praias do extremo NW e as mais grossas nas porçóes centrais. Estas características sedimentológicas refletem as condiçôes morfodinâmicas inerentes de cada setor da faixa praial. A variação nos valores modais indica que há ocorrência de sedimentos de fontes distintas. Neste caso, além da plataforma interna adjacente, os campos de dunas, e os rios Pacoti e Cocó contribuem como uma importante fonte de material siliciclástico às praias adjacentes e, ainda, quando há redução no transporte normal dos grãos de areia, com a presença dos beachrocks, modificando os níveis de energia.

Os resultados apontam para o predomínio de areia média a grossa, junto às desembocaduras dos rios Pacoti e Cocó. A areia grossa é resultado da erosão e intemperismo dos sedimentos formadores dos cordóes de arenitos de praia (beachrocks). Já os sedimentos de textura areia média são provenientes dos campos de dunas móveis, que são transportados pelos ventos alísios de $\mathrm{SE}$ e $\mathrm{NE}$, assoreiam os canais dos rios, e são levados e distribuídos pela faixa praial por meio das ondas e corrente de deriva litorânea no sentido NW. Ressalta-se ainda a contribuição dos sedimentos, de textura areia média a grossa, da Formação Barreiras (Tabuleiros Pré-litorâneos) que por meio da descarga fluvial, principalmente no período chuvoso, são também espalhados pela corrente de deriva litorânea ao longo da costa no mesmo sentido.

Evidenciou-se uma reduçáo no tamanho médio dos grãos na direção NW, o que pode ser explicado pelo distanciamento das faixas descontínuas dos beachrocks e desembocaduras fluviais.

Foram observadas variações significativas na face de praia ao longo da costa. Porém, nos três setores há um padrão bem definido dos perfis morfodinâmicos praiais associados à sazonalidade meteorológica, apresentando perfis de inverno nos períodos de transição e estiagem e perfis de verão no período chuvoso.

A presença de bancos e calhas longitudinais é uma constante na área pesquisada, apresentam-se fortemente associados aos períodos de transição e estiagem, em razão da ocorrência de ventos mais intensos e ondas de tempestade mais frequentes que retiram sedimentos do pós-praia e dunas frontais para a formação dos bancos. Entretanto, quando da ocorrência de ressacas no período chuvoso, perfis de inverno são formados.

Em relaçáo aos percentuais de distribuição das classes granulométricas ao longo dos pontos monitorados, o póspraia dos três setores apresentou a menor variabilidade, em comparaçáo aos demais subambientes. Os sedimentos foram classificados em areia média com grau de seleção moderadamente selecionado.

A declividade do estirâncio apresenta baixos valores (entre $7,2^{\circ}$ e $1,6^{\circ}$ ). $\mathrm{O}$ caráter mais dissipativo é observado no extremo NW, associado às condiçôes de alta energia e suprimento abundante de sedimentos, apresentando uma tendência fortemente progradante. Este processo é corroborado por Marino \& Freire (2013), por meio de análises da variação da linha de costa, os quais constataram que a Praia do Futuro (Setor 3) é alimentada pela erosão das praias situadas à barlamar e também pelos sedimentos transportados pelos rios Pacoti e Cocó. As areias resultantes são transportadas até o espigão do Titanzinho, que impede a continuidade do transporte e propicia o intenso acúmulo de sedimentos. Nessa área o bypass costeiro acha-se quase completamente erradicado em função da urbanização associada ao crescimento da cidade de Fortaleza em direção leste.

\section{CONCLUSÓES}

1. Pode-se observar que esta faixa litorânea permitiu o desenvolvimento de praias com níveis diferenciados de energia hidrodinâmica: expostas e semiexpostas, protegidas pelas faixas alongadas e descontínuas dos arenitos de praia, os quais diminuem a energia das ondas, protegendo as praias da erosão costeira;

2. Os setores extremos são os mais dinâmicos e de maior susceptibilidade a ação das ondas e ressacas;

3. A dinâmica sedimentar é caracterizada pela grande mobilidade de sedimentos ao longo da praia em resposta a ação das correntes de deriva litorânea e entre a parte emersa e submersa da mesma em resposta às variaçóes meteorológicas;

4. Por encontrar-se inserida totalmente na RMF, a planície costeira entre as praias do Futuro e do Porto das Dunas sofreu e sofre fortemente as consequências negativas de um rápido processo de urbanização e adensamento demográfico, trazendo desequilíbrios significativos nas relaçôes sociedade versus natureza e tendo como efeitos mais marcantes a degradação ambiental.

\section{RECOMENDAÇÃO}

Recomenda-se para futuros trabalhos a realização de sondagens estratigráficas ao longo da planície costeira, a análise de detalhe dos sedimentos quanto à morfoscopia e mineralogia, o monitoramento morfodinâmico e sedimentológico da faixa praial, a batimetria e faciologia da antepraia e plataforma continental interna adjacente, e a realização de estudos prévios (muitas vezes de médio e longo prazo) para a construção de obras e empreendimentos costeiros, sobretudo em se tratando de ambientes dinâmicos, como é o caso.

\section{AGRADECIMENTOS}

Os autores agradecem ao Programa de Pós-graduação em Geologia da Universidade Federal do Ceará (UFC), ao Laboratório de Geologia Marinha Aplicada - UFC, e ao Laboratório de Química Ambiental da Universidade de Fortaleza, nas pessoas da Profa Denise Fernandes, Oyrton Monteiro Júnior e bolsistas dos Programas PROBIC e PAVIC, em especial pelas análises laboratoriais efetuadas. 


\section{REFERÊNCIAS}

Bascom, W.N. (1951) - The relationship between sand-size and beach face slope. Transactions, American Geophysical Union (ISSN 2324-9250), 32(6):866-874, Washington, DC, U.S.A.

Bensi, M. (2006) - Aplicação do correntômetro acústico ADCP em ambientes marinhos e estuarinos do Ceará e Paraíba - nordeste do Brasil. 134p, Dissertação de Mestrado, Universidade Federal do Ceará, Fortaleza, CE, Brasil. Available at http://www.repositorio.ufc.br:8080/ri/ bitstream/123456789/1308/1/2006_dis_mbensi.pdf.

Bowen, A.J.; Inman, D.L. (1966) - Budget of littoral in the vicinity of point Arguello, California. 56p., U.S. Army Coastal Engineering Research Center, Technical Memorandum 19, Fort Belvoir, VA, U.S.A. Available at http://repository.tudelft.nl/assets/uuid:ced71bcf-88624f9d-b04c-1da28c101fcb/TLN1001001.pdf.

Castilhos, J.A. (1995) - Estudo evolutivo, sedimentológico e morfodinâmico da planície costeira e Praia da Armação - Ilha de Santa Catarina, SC. Florianópolis, 134p., Dissertação de Mestrado, Universidade Federal de Santa Catarina, SC, Brasil. Não publicado.

Dal Cin, R.; Simeoni, U. (1994) - A model for determining the classification, vulnerability and risk in the southern coastal zone of the Marche (Italy). Journal of Coastal Research (ISSN 1551-5036), 10(1):18-29, Fort Lauderdale, FL, U,S.A. Available at http://www.jstor. $\mathrm{org} /$ stable/4298189

Folk, R.L.; Ward, C. (1957) - Brazos river bar: a study in the significance of grain size parameters. Journal of Sedimentary Petrology, (ISSN 1073-130X), 27(1):3-26, Tulsa, Ok, U.S.A.

King, C.A.M. (1972) - Beaches and coasts. 570p., Edward Arnold, London, U.K. ISBN: 0713156090.

Komar, P.D. (1976) - Beach processes and sedimentation.429p., Prentice Hall, New Jersey, USA. ISBN: 0130725951.

Krumbein, W.C. (1934) - Size frequency distribution of sediments Journal of Sedimentary Petrology, 4(2):65-77. DOI: 10.1306/D4268EB9-2B26-11D7$8648000102 \mathrm{C} 1865 \mathrm{D}$

Lima, S.F.; Silva Filho, W.F. ;Pinheiro, R.D.; Freire, G.S.S.; Maia, L.P; Monteiro, L.H.U. (2001) - ANASED Programa de análises, classificação e arquivamento de parâmetros metodológicos. Anais do VIII Congresso da Associaçáo Brasileira de Estudos do Quaternário (ABEQUA), CD-ROM, p. 458-459. Mariluz, Imbé, RS, Brasil.

Mallmann, D.L.B. (2008) - Vulnerabilidade do litoral sul de Pernambuco à erosão. 145p., Dissertação de Mestrado, Universidade Federal de Pernambuco, Recife, PE, Brasil. Disponível em http://www.dominiopublico.gov.br/ pesquisa/DetalheObraForm.do? select_action $=\& \mathrm{co}_{-}$ obra $=99077$

Mazzer, A.M. (2007) - Proposta metodológica de análise de vulnerabilidade da orla marítima à erosão costeira: aplicação na costa sudeste da ilha de Santa Catarina, Florianópolis-SC, Brasil.169p., Dissertação de Doutorado, Universidade Federal do Rio Grande do Sul, Porto Alegre, RS, Brasil. Não publicado

Marino, M.T.R.D.; Freire, G.S.S. (2013) - Análise da evoluçáo da linha de costa entre as praias do Futuro e Porto das Dunas, Região Metropolitana de Fortaleza
(RMF), estado do Ceará, Brasil. Revista Gestão Costeira Integrada, 13(1):113-129. DOI: 10.5894/rgci373

Marino, M.T.R.D.; Freire, G.S.S.; Horn Filho, N.O. (2012) - Aspectos geológicos e geomorfológicos da zona costeira entre as praias do Futuro e Porto das Dunas, Ceará, Brasil. Revista de Geologia, (ISSN 01032410), 25(1):77-96, Fortaleza, CE, Brasil. Available at http://www.revistadegeologia.ufc.br/documents/ revista/2012/06_2012.pdf

Molisani, M.M.; Cruz, A.L.V.; Maia, L.P. (2006) Estimativa da descarga fluvial para os estuários do estado do Ceará, Brasil. Arquivos de Ciências do Mar (ISSN: 0374-5686), 39:53-60, Fortaleza, CE, Brasil. Available at http://www.institutomilenioestuarios.com.br/pdfs/ Produtos/019/19_Molisanietal2007a.pdf

Morais, J.O. de (1980) - Aspectos do transporte de sedimentos no litoral do município de Fortaleza, estado do Ceará. Arquivos de Ciências do Mar (ISSN 03745686), 20:71-100, Fortaleza, CE, Brasil. Available at http://www.labomar.ufc.br/images/stories/arquivos/ ArqCienMar/V20_1980/acm_1980_20_1-2_07.pdf

Nordstrom, K.F. (1981) - Differences in grain size distributions with shoreline positions in a spit environment. Northeastern Geology (ISSN 0194-1453), 3:252-258. New York, USA.

Nuber, E.; Klein, A.H.F.; Calliari. L.J. (2006) - Foreshore morfodynamic changes in a bimodal sediment beach. Journal of Coastal Research (ISSN 0749-0208), SI39:660663, Proceedings of the $8^{\text {th }}$ International Coastal Symposium, SC, Brazil. Available at http://siaiacad09. univali.br/ics2004/arquivos/133_nuber.pdf

Ribeiro, J.A.P. (2001) - Características hidrogeológicas e hidroquímicas da faixa costeira leste da Região Metropolitana de Fortaleza - Ceará. 112p, Dissertação de Mestrado, Universidade Federal do Ceará, Fortaleza, CE, Brasil. Não publicado.

Shepard, F.P. (1954) - Nomenclature based a sand-silt-clay rations. Journal of Sedimentary Petrology, 24(3):151158. DOI: 10.1306/D4269774-2B26-11D7$8648000102 \mathrm{C} 1865 \mathrm{D}$

Short, A. (1999) - Handbook of beach and shoreface morphodynamics. 379p., John Wiley \& Sons, Chichester, U.K., New York, Ny, U.S.A. ISBN: 0471965707.

Sonu, C.J. (1972) - Bimodal composition and cyclic characteristics of beach sediment in continuously changing profiles. Journal of Sedimentary Petrology, 42(4):852-857. DOI: 10.1306/74D72653-2B21-11D7$8648000102 \mathrm{C} 1865 \mathrm{D}$

SRH (2005) - Atlas eletrônico dos recursos hidricos e meteorológicos do Ceará. Secretaria de Recursos Hídricos do Estado do Ceará. Fortaleza, CE, Brasil. In: http:// atlas.srh.ce.gov.br (acedido em Setembro 2012).

Wentworth, C.K. (1922) - A scale of grade and class terms for classic sediments. Journal of Geology, 30(5):377-392. DOI: $10.1086 / 622910$

Wentworth, C.K. (1933) - Fundamental limits to the sizes of clastic grains. Science (ISSN 0036-8075), 30(77):633634, Washington, DC, U.S.A.

Wright, L.D.; Short, A.D. (1984) - Morphodynamic variability of surf zones and beaches: a synthesis. Marine Geology, 56(1-4):93-118. DOI: 10.1016/00253227(84)90008-2 